\title{
Reducing global environmental inequality: Determining regional quotas for environmental burdens through systems optimisation \\ Dol:
}

10.1016/j.jclepro.2020.121828

\section{Document Version}

Accepted author manuscript

Link to publication record in Manchester Research Explorer

Citation for published version (APA):

Pozo, C., Galán-martín, A., Cortés-borda, D., Sales-pardo, M., Azapagic, A., Guimerà, R., \& Guillén-gosálbez, G. (2020). Reducing global environmental inequality: Determining regional quotas for environmental burdens through systems optimisation. Journal of Cleaner Production, 270, [121828]. https://doi.org/10.1016/j.jclepro.2020.121828

Published in:

Journal of Cleaner Production

\section{Citing this paper}

Please note that where the full-text provided on Manchester Research Explorer is the Author Accepted Manuscript or Proof version this may differ from the final Published version. If citing, it is advised that you check and use the publisher's definitive version.

\section{General rights}

Copyright and moral rights for the publications made accessible in the Research Explorer are retained by the authors and/or other copyright owners and it is a condition of accessing publications that users recognise and abide by the legal requirements associated with these rights.

\section{Takedown policy}

If you believe that this document breaches copyright please refer to the University of Manchester's Takedown Procedures [http://man.ac.uk/04Y6Bo] or contact uml.scholarlycommunications@manchester.ac.uk providing relevant details, so we can investigate your claim.

\section{OPEN ACCESS}




\title{
Reducing global environmental inequality: Determining regional quotas for environmental burdens through systems optimisation
}

\author{
C. Pozo ${ }^{1 \dagger}$, A. Galán-Martín ${ }^{2,3 \dagger}$, D. Cortés-Borda ${ }^{3 \dagger}$, M. Sales-Pardo ${ }^{3}$, A. Azapagic ${ }^{4}$, R. Guimerà ${ }^{3,5^{*}}$, G. \\ Guillén-Gosálbez ${ }^{2 *}$ \\ ${ }^{1}$ LEPAMAP research group, University of Girona, C/ Maria Aurèlia Capmany 61, 17003 Girona, Spain \\ ${ }^{2}$ Institute for Chemical and Bioengineering, Department of Chemistry and Applied Biosciences, ETH \\ Zürich, Vladimir-Prelog-Weg 1, 8093 Zürich, Switzerland \\ ${ }^{3}$ Departament d'Enginyeria Química, Universitat Rovira i Virgili, 43007 Tarragona, Spain \\ 4 Department of Chemical Engineering and Analytical Science, The University of Manchester, \\ Sackville Street, Manchester M13 9PL, UK \\ ${ }^{5}$ Institució Catalana de Recerca i Estudis Avançats, 08010 Barcelona, Spain
}

${ }^{\dagger}$ C.P, A.GM and D.CB are co-first authors.

*Corresponding authors:

\author{
gonzalo.guillen.gosalbez@chem.ethz.ch \\ adisa.azapagic@manchester.ac.uk \\ roger.guimera@urv.cat
}

\begin{abstract}
Reducing inequality is essential for sustainable development, yet our understanding of its many dimensions and driving forces is still limited. Here we study the global distribution of 25 environmental burdens encompassing natural resources (water, materials and land use) and air emissions, all related to activities underpinning human welfare. We find large disparities in inequality levels across burdens and a general, yet slow, decline in inequality in the period 1995-2009, explained mostly by the faster economic growth of emerging economies. Acknowledging that allocation issues may hamper greater equality, we propose a framework for an optimal allocation of quotas for environmental burdens respecting a maximum allowable inequality limit while ensuring a safe operation within the Earth's ecological capacity. Our results shed light on the global distribution of environmental burdens and provide a roadmap for achieving a greater environmental equality using systems optimisation. It is hoped that this work will trigger further discussion on the need to address environmental inequality, currently missing in the Sustainable Development Goals, and open up new research avenues on the use of whole-systems approaches in solving global sustainability problems.
\end{abstract}

Keywords: environmental inequality; sustainability; input-output analysis; inequality drivers; target; system optimisation

\section{Introduction}

In the 2030 Agenda for Sustainable Development, the UN member states defined a path towards sustainable progress that identified inequality within and across countries as a major obstacle for a sustainable future (United Nations, 2015a, 2015b). Inequality undermines economic growth and hinders social cohesion and stability which calls for urgent action to address its root causes (Alesina and Perotti, 1996; Bourguignon, 2004; Cingano, 2014). Despite past and current efforts geared towards reducing inequality, the wealth is still accumulating in the richest nations (Birdsall, 2002; Westing, 1986) and citizens (Jones, 2016; Saez and Zucman, 2016), hampering greater equality.

Economic and social inequalities within and across countries have been extensively studied, particularly income (Cingano, 2014; Easterly et al., 2006) and gender inequality (Ridgeway, 2011; Sen, 2001), yet their environmental counterpart is still poorly understood. Environmental inequality concerns disparities in the access to natural resources and pollution levels and exposure, which tend to emerge as a result of economic activities underpinning human welfare (Jelin et al., 2017; Naeem et al., 2016). We here analyse this inequality type, often disregarded in previous works despite its links to economic and social inequalities (UNESCO, ISSC and IDS, 2016), delving into its temporal evolution and drivers, highlighting the need to incorporate its study in the sustainability agenda and providing a method to keep it within acceptable limits. 
To this end, we analyse how environmental burdens related to air emissions and consumption of natural resources are distributed among nations. Ensuring a fair distribution of these burdens matters as it reflects a fundamental sustainability goal linked to the concept of environmental justice, i.e. all human beings should have the same right to use resources equally (Schlosberg, 2013; Soja, 2010; Walker, 2009). Furthermore, studying the distribution of burdens is key for articulating future negotiations aiming at their equitable reallocation and control as countries will only take action if the deal is perceived to be fair (Tavoni et al., 2011; Vasconcelos et al., 2014).

Ensuring a safe operating space for sustainable development will, therefore, require enforcing limits on total burdens below the Earth's ecological capacity, here referred to as the vertical dimension of sustainability (Griggs et al., 2014; Leach et al., 2013; Sterner et al., 2019). These quotas on burdens should in turn be allocated among countries in a fair manner, what we term here the horizontal dimension of sustainability. These two dimensions are at present treated separately (Griggs et al., 2013; Sustainable agriculture, 2018), although here we argue that they could be handled concurrently via appropriate methods.

Previous efforts on environmental inequality focused on analysing the distribution of carbon emissions (Duro and Padilla, 2006; Pan et al., 2014; Teng et al., 2011), on correlating emissions with income inequality (Padilla and Serrano, 2006) and on providing prospects on carbon-emissions inequality (Heil and Wodon, 2000). In contrast, fewer studies assessed inequality in other environmental indicators, such as air pollutants and their toxicity (Boyce et al., 2016), natural resources and materials (Hedenus and Azar, 2005; Teixidó-Figueras et al., 2016), and the ecological footprint of different burdens (Duro \& Teixidó-Figueras, 2013; Teixidó-Figueras \& Duro, 2015; Teixido-Figueras \& Duro, 2012). Going far beyond previous research, this work provides a full analysis of current inequality levels across a wide range of environmental burdens (25 in total) related to resource consumption and emissions to the environment. In addition, we analyse for the first time their temporal evolution and identify their major drivers. Finally, building on the outcome of these analyses, we propose a novel systems optimisation tool to allocate per-capita quotas on burdens across countries to keep inequality within an acceptable range while not exceeding the planetary boundaries. This approach, therefore, integrates both the horizontal and vertical sustainability dimensions within a single framework which could be used to support policy-making in the definition and implementation of targets to promote greater environmental equality.

Our analysis is based on multi-regional environmentally-extended input-output (MREEIO) tables covering 25 environmental indicators over the period 1995-2009, i.e. all the years available in the World Input Output Database (WIOD), from where data were retrieved (Dietzenbacher et al., 2013; Timmer et al., 2012). These indicators quantify environmental burdens related to resource consumption (inputs to economic sectors) and emissions to the environment (outputs from sectors), which are split across four categories: materials, water, land and emissions. These 25 burdens, responsible for different global, regional and local impacts (e.g. climate change, acidification, water scarcity, resource depletion and land use) are quantified following a consumption-based (CB) accounting approach. The CB perspective, fully consistent with the concept of environmental justice, considers the burdens embodied in the goods or services consumed or provided in a country. These include domestic burdens and those embodied in trade through imports and exports (Davis and Caldeira, 2010; Jorgenson et al., 2019). Hence, we study life cycle burdens (i.e. the environmental footprint) generated across global supply chains that cover a given national demand.

To evaluate inequality, we use the Gini coefficient (Dorfman, 1979), an index originally developed to assess economic inequality (Allison, 1978) and more recently adopted to study environmental inequality (Qian et al., 2019; Teixido-Figueras et al., 2016). A Gini coefficient of zero reflects perfect equality, whereby all citizens or countries have equitable access to resources or are responsible for the same amount of emissions to the environment. A Gini value of one indicates maximum inequality, where a single person or country uses all the resources or is responsible for all the environmental emissions. In the absence of data for some of the domestic distribution of wealth, use of resources and environmental emissions, we assume that these distributions are uniform within each country. This leads to what is known as a "type two inequality", which provides a lower bound on the "true" inequality level among citizens (Milanovic, 2013). Additionally, we study the evolution of inequality in 1995-2009 and use decomposition techniques to analyse the main factors driving inequality changes. Finally, we envision a roadmap towards sustainability, where the integration between the vertical and 
horizontal sustainability dimensions is achieved via systems optimisation. The quotas on environmental burdens are computed according to a given criterion (e.g. minimum deviation from the current status quo) while satisfying the limits on the planetary boundaries. Specific details of our approach and the underlying data, including a discussion of the study limitations, can be found in the Methods section and in the Supplementary Material sections 2.5 to 2.7.

Our analysis reveals significant disparities in inequality levels across environmental burdens (Ginis from 0.23 to 0.71 ), with the economic activities in the primary sector being more equally distributed than those generated by industry (secondary sector). We also find that equality is increasing in 22 of the 25 burdens, but at a too slow a pace that may threaten long-term sustainable development. This improvement in equality of the burdens distribution was driven by changes in the size and structure of the economies, but slowed down by demographic and technological factors.

Our results highlight the need to develop tailored policies to bring and keep inequality in the burdens distribution within the desired range and in a sustainable manner. In the absence of any inequality targets agreed internationally, we propose a roadmap that establishes quantitative limits on the Ginis of environmental burdens considering their role in satisfying basic human needs and their current level of inequality. These inequality targets are subsequently translated into optimal regional percapita quotas by means of the proposed systems optimisation approach. We illustrate how this framework would work in practice by calculating regional quotas for consumption-based $\mathrm{CO}_{2}$ emissions that would allow reducing global inequality by $20 \%$ and curbing total emissions by $61 \%$, while deviating the least from the current status quo.

\section{Methods}

We combine several analytical tools to assess the environmental inequality. First, data from MREEIO models are employed to quantify environmental burdens in every nation following a CB perspective over the period 1995-2009. Then, the environmental inequality is assessed using the Gini coefficient to investigate its dynamic trends. Moreover, an additive decomposition method is applied to identify the main factors driving inequality changes. Finally, the insight generated by these methods is used to develop a systems optimisation framework that allocates per capita CB quotas to reduce inequality effectively. All these methods and calculations are explained in more detail below and in section 2 in the Supplementary Material.

\subsection{Multi-regional environmentally-extended input-output approach}

Each of the environmental burdens $b$ generated by each country $r\left(w r_{r b}^{C B}\right)$ was calculated using the WIOD database (Dietzenbacher et al., 2013; Timmer et al., 2012) and the Leontief inverse (see section 2.2 in the Supplementary Material for further details) following a CB approach. The WIOD database covers 35 economic activities and 70 environmental indicators for 40 countries (representing more than $85 \%$ of the world's GDP), plus the rest of the world (RoW) region encompassing the remaining countries (Supplementary Table 2). The data span the period from 1995 to 2009. Hence, we restrict the analysis to these years due to lack of data outside this period. The 70 burdens are classified into five categories: use of materials, water, land and energy, as well as air emissions. We select 25 of the 70 indicators available (see Supplementary Table 3 ) by omitting energy indicators and burdens labelled as "others". We disregard energy indicators as we focus on the resulting environmental burdens rather than on the source energy accounts, which exclude the energy assets (responsible for the burdens). Burdens within the "others" category are also omitted as they embed highly aggregated data. In the materials category, we combine the "used" and "unused" materials into a single indicator to consider both the share of burden entering the economy (used) as well as the amount of material extracted from the environment but not entering any economic activity (unused).

\subsection{Inequality assessment via Gini coefficients}

Gini coefficients (Allison, 1978) for each burden $b\left(\right.$ Gini $\left._{b}\right)$ were calculated from the disparities in percapita burdens between every two world regions $r$ and $r^{\prime}$ in a particular year (yielding a total of $2\left(\begin{array}{c}|r| \\ 2\end{array}\right)=$ 1640 combinations), as shown in Eq. (1): 


$$
\operatorname{Gini}_{b}=\frac{\sum_{r} \sum_{r^{\prime} \neq r} \text { pop }_{r} \operatorname{pop}_{r^{\prime}}\left|\frac{w r_{r b}^{C B}}{\operatorname{pop}_{r}}-\frac{w r_{r^{\prime} b}^{C B}}{p o p_{r^{\prime}}}\right|}{2 \sum_{r} \operatorname{pop}_{r} \sum_{r} w r_{r b}^{C B}} \quad \forall b
$$

Here, $\operatorname{pop}_{r}\left(\right.$ pop $\left._{r^{\prime}}\right)$ denotes the population of region $r\left(r^{\prime}\right)$ and $w r_{r b}^{C B}\left(w r_{r^{\prime} b}^{C B}\right)$ represents the CB burden $b$ of region $r(r)$ (e.g. emissions of $\mathrm{CO}_{2}$ occurring domestically as well as in the rest of the world to satisfy the demand of country $r$ ). These burdens are calculated from the annual CB economic output required to cover the demand of a country, $X^{\mathrm{CBr}}$ (in US\$), the corresponding burden intensity relative to the economic output, $B I_{b}$ (in burden units $/ \$$, e.g. $\mathrm{kg} \mathrm{SO}_{2}$ eq./\$), and the annual total burden generated by households, $\mathrm{HH}_{r b}$ (in burden units, e.g. kg SO $\mathrm{S}_{2}$ eq.) as shown in Eq. (2).

$$
w r_{r b}^{C B}=B I_{b} X^{\mathrm{CBr}}+H H_{r b} \quad \forall r, b
$$

Note that $X^{\mathrm{CBr}}$ corresponds to the total annual output of the world economy required to meet the demand of a country (see section 2.2. in the Supplementary Material). To calculate the economic Gini, we used the GDP values corrected for purchasing power parity (PPP, GDPPPP) provided by the World Bank (2017), except for Taiwan, which was sourced from the World Economic Outlook (International Monetary Fund, 2011) corrected for PPP with the conversion factor provided by the World Data Bank for China. The GDPPPP for the RoW was obtained by subtracting the GDPPPP of the 40 countries in the WIOD from the world GDPPPP provided by the World Bank. Population data were also retrieved from the World Bank except for Taiwan, for which we used the World Economic Outlook (International Monetary Fund, 2011). The population of the RoW was estimated by subtracting the population of the 40 countries in the WIOD from the world population provided by the World Bank.

\subsection{Temporal decomposition}

To investigate the main drivers of inequality, we employed the additive decomposition method developed by Biewen $(2012,2014)$. Following this approach, the Gini change between two consecutive years is decomposed into the ceteris paribus contributions of four factors plus the interactions occurring between them (Eqs. (3) to (7)): (i) a demographic factor corresponding to the population (pop); (ii) an economic factor related to changes in the total economic output $\left(X^{\mathrm{CBr}}\right)$; (iii) a technological factor modelling changes in burden intensity (BI); and (iv) the households factor covering changes in direct burdens generated by households $(\mathrm{HH})$. The decomposition takes the following form:

$$
\begin{aligned}
\operatorname{Gini}_{b}^{1111}- & \operatorname{Gini}_{b}^{0000}=\left(\operatorname{Gini}_{b}^{1000}-\operatorname{Gini}_{b}^{0000}\right) \\
& +\left(\text { Gini }_{b}^{0100}-\operatorname{Gini}_{b}^{0000}\right) \\
& +\left(\text { Gini }_{b}^{0010}-\operatorname{Gini}_{b}^{0000}\right) \\
& +\left(\text { Gini }_{b}^{0001}-\text { Gini }_{b}^{0000}\right) \\
& + \text { Interactions }_{b} \quad \forall b
\end{aligned}
$$

where the superscripts in Ginideth denote each of the four factors: $d$ for demographic, e for economic, $t$ for technological and $h$ for household. Note that the economic factor considers both changes in the total output of an economy and also in its structure, thus partially capturing improvements in technology efficiency (i.e. sectors that become more efficient consume less from other sectors). However, here we use the term "technology" in the same spirit as in the widely-used IPAT equation (which determines the environmental impact related to population, affluence and technology), thereby referring only to the improvements affecting burden intensities.

The value of the superscript (either 0 or 1 ) indicates whether the corresponding factor is evaluated in the first $(=0)$ or second $(=1)$ year. For example, in the assessment of the Gini changes taking place between 1995-1996, the superscript 0000 denotes that population, economic outputs, burdens intensities and burdens from households are set to their values in 1995. On the other hand, 1111 
indicates that the four factors are set to their values in 1996. Similarly, the superscript 0010 denotes that population, economic outputs and burdens from households are fixed to their values in 1995, while burden intensities are those in 1996. Hence, Eqs. (3-6) provide the ceteris paribus contributions that are corrected with the Interactions term following the principle of "jointly created and equally distributed"(Sun, 1998) to finally obtain the total contribution of each factor (see section 2.3 in the Supplementary Material for further details). The values reported for each indicator correspond to the average contributions across all the different pairs of years during the period 1995-2009. All monetary values are expressed in 1995 US $\$$ to eliminate the effect of inflation on the calculations.

\subsection{Regional decomposition}

Inequalities result from disparities in per-capita burdens between countries. In order to identify the main contributors to the global level of inequality, we decompose the CB Ginis into regional terms using Eq. (8):

$$
\operatorname{GiniR}_{r b}=\frac{\sum_{r^{\prime} \neq r} \text { pop }_{r} \operatorname{pop}_{r^{\prime}}\left|\frac{w r_{r b}^{C B}}{p o p_{r}}-\frac{w r_{r^{\prime} b}^{C B}}{p o p_{r^{\prime}}}\right|}{2 \sum_{r} p o p_{r} \sum_{r} w r_{r b}^{C B}} \forall r, b
$$

where $\operatorname{GiniR}_{r b}$ denotes the contribution of region $r$ to the total inequality level for burden $b$. Note that the summation over $r$ of all the regional contributions yields the total CB Gini of the burden (i.e. $\sum_{r} \operatorname{Gini}_{r b}=$ Gini $_{b}$ ). In this work, the regional contribution is obtained by first applying Eq. (8) for all of the years between 1995 and 2009 and then computing the average over the whole period.

\subsection{Optimisation model for reducing inequality}

As mentioned earlier, our results highlight the need to develop tailored policies to control inequality levels. In the absence of any inequality targets agreed internationally, we suggest a quantitative roadmap towards environmental equality based on two steps. In the first step, quantitative targets are imposed on the burdens' distributions (i.e. on their Ginis) considering their current inequality level and the role played in satisfying basic human needs (see section 3.4). Then, these Gini targets are translated into regional quotas for per-capita CB burdens by solving an optimisation model based on nonlinear programming (NLP). The NLP model seeks regional quotas deviating the least from the current $\mathrm{CB}$ burdens that in turn satisfy the following constraints: (i) an upper bound on inequality (quantified via the Gini coefficient); (ii) a maximum disparity in per-capita burdens across regions; and (iii) a limit on the total burden that can be generated globally. The need to consider these constraints in the model arises from the results of the previous analysis, as discussed later in the manuscript. Finally, the optimisation model can be expressed as follows (Eqs. (13-16)):

$$
\begin{gathered}
\min \sum_{r} \frac{\left|P C_{r}-\mathrm{PC}_{\mathrm{r}}^{\mathrm{REF}}\right|}{\mathrm{PC}_{\mathrm{r}}^{\mathrm{REF}}} \\
\text { s.t. } \frac{\sum_{r} \sum_{r \prime \neq r} \text { pop }_{\mathrm{r}} \mathrm{pop}_{\mathrm{r},}\left|P C_{r}-P C_{r^{\prime}}\right|}{2 \sum_{r} \mathrm{pop}_{\mathrm{r}} \sum_{r}\left(P C_{r} \mathrm{pop}_{\mathrm{r}}\right)} \leq \overline{\text { Gini }} \\
\sum_{r}\left(P C_{r} \mathrm{pop}_{\mathrm{r}}\right) \leq \overline{\mathrm{TB}} \\
\left|P C_{r}-P C_{r^{\prime}}\right| \leq \overline{\mathrm{DISP}} \quad \forall r, r^{\prime} \\
P C_{r} \in \mathbb{R}_{\geq 0} \quad \forall r
\end{gathered}
$$

where the objective function (Eq. (13)) seeks to minimise the relative total change (in absolute value) between the current $\mathrm{CB}$ per-capita burden (parameter $\mathrm{PC}_{\mathrm{r}}^{\mathrm{REF}}$ ) and the optimal $\mathrm{CB}$ targets (denoted by variable $P C_{r}$ ) for all regions $r$. Eqs. (14) and (15) impose an upper bound on the inequality level (parameter $\overline{\text { Gini) }}$ as well as on the total burden generated globally (parameter $\overline{\mathrm{TB}}$ ), respectively. Finally, Eq. (16) forces the maximum disparities in per-capita burdens between countries to lie below a desired upper level (parameter $\overline{\mathrm{DISP}}$ ). Hence, Eqs. (14-16) ensure a safe operation consistent with the Earth's ecological capacity and maximum allowable inequality levels, thus integrating both the vertical and horizontal dimensions of sustainability. All variables (depicted in italics in this model) and parameters (normal font) are defined for the desired policy horizon, except for those with superscript 
REF, which apply to the reference year (2009 in this case). Note that the optimisation model may provide per-capita quotas $\left(P C_{r}\right)$ above current burdens generation levels. This would allow higher pollution and consumption in some regions to lower global inequality levels. Due to economic growth, emerging countries are expected to increase their per-capita CB burdens. However, this might not be necessarily the case if they manage to decouple the GDP from environmental degradation, which has been already observed in some developing countries (Ma et al., 2019). In this regard, the CB percapita quotas derived from our model should be understood as an upper limit on the per-capita CB burdens; hence, there is no need to force countries artificially to satisfy their quota as a strict equality.

With regard to the data, estimates for the future population of each region $r$ (parameter pop p $_{\mathrm{r}}$ were taken from the UN populations prospects assuming a medium variant scenario (United Nations, 2017). Planetary boundaries on burdens $\overline{\mathrm{TB}}$ are only available for a handful of indicators, such as $\mathrm{CO}_{2}$, nitrogen or blue water (Hoekstra and Wiedmann, 2014; Kwakkel and Timmermans, 2012; Rockström et al., 2009b, 2009a; Steffen et al., 2015), but we anticipate that future research might bring more into play. When analysing a burden for which a global limit is missing, Eq. (15) should simply be omitted from the model. To aid the calculations, the NLP model is reformulated into an equivalent linear programming (LP) formulation following standard mathematical techniques (see section 2.5 in the Supplementary Material). The model proposed here can also be expanded to incorporate additional constraints to reflect different interests, priorities and concerns from diverse stakeholders as well as particular characteristics of the burdens under consideration, such as local environmental impacts or vulnerabilities.

\section{Results}

This section presents the results of the analyses discussed above, with their implications and conclusions discussed in the subsequent sections.

\subsection{Assessment of environmental inequality}

To get a clear picture of where we stand in terms of inequality in $C B$ burdens distribution, we start by computing environmental Gini coefficients over the period 1995-2009 (Fig. 1). To support the analysis of the results, we define five environmental inequality bands and classify the burdens according to their CB Gini value: low (Ginis between 0-0.2), moderate (0.2-0.4), considerable (0.4-0.6), high (0.6$0.8)$ and very high (0.8-1) (Fig. 1).

No burdens are found in the low or very high inequality levels, while large disparities are observed in inequality levels across burdens, which seem to be strongly connected to the economic activities generating them. These economic activities belong to either the primary, secondary, tertiary or household sectors (European Commission, 2017) (Fig. 2 and section 2.6), where the first is more closely connected to basic human needs (e.g. food and water burdens) (Rosa and Dietz, 2012), while the rest are mostly linked to comforts and luxuries (Campbell, 1998; Jackson, 2005; Wilk, 2002). The lowest CB Ginis, falling within the moderate inequality band (CB Ginis between 0.20 and 0.40 ), correspond to burdens primarily related to basic human needs, such as food production and water supply (see Fig. 2). This group includes green water (rainfall), $\mathrm{NH}_{3}$ and $\mathrm{N}_{2} \mathrm{O}$ emissions (which mostly come from the application of fertilisers and livestock), most land indicators (arable land, crops and pastures) as well as all biomass-based burdens (animals, feed, food and forestry). All these burdens are strongly linked to the economic activity Agriculture, Hunting, Forestry and Fishing in the primary sector. Some other burdens display also moderate inequality levels while not being related only to the primary sector. These include blue and grey water (ground/surface water and polluted water, respectively) and emissions of $\mathrm{CH}_{4}, \mathrm{NO}, \mathrm{SO}, \mathrm{CO}$ and NMVOC. For these burdens, smaller contributions from the primary sector, which reflects weaker links to basic human needs, tend to lead to larger Ginis.

Burdens within the next band, considerable inequality, show Gini values between 0.40 and 0.60 and lie close to the economic Gini (0.48). This group includes $\mathrm{CO}_{2}$ emissions and oil extraction, which have been shown to correlate strongly with the GDP (Al-Iriani, 2006; Apergis and Payne, 2010; Lim et al., 2014; Saidi and Hammami, 2015). It also contains coal and other materials, such as construction and metals. These burdens are linked mostly to the secondary sector and feature very small contributions (if any) from the primary sector (Fig. 2). The only exception within this group in terms of sectoral breakdown is forest land, which despite being fully related to the primary sector shows a Gini 
of 0.52 . This higher inequality level, compared to the other burdens connected mostly to the primary sector, could be attributed to the natural geographical distribution of this resource with significant disparities across regions.

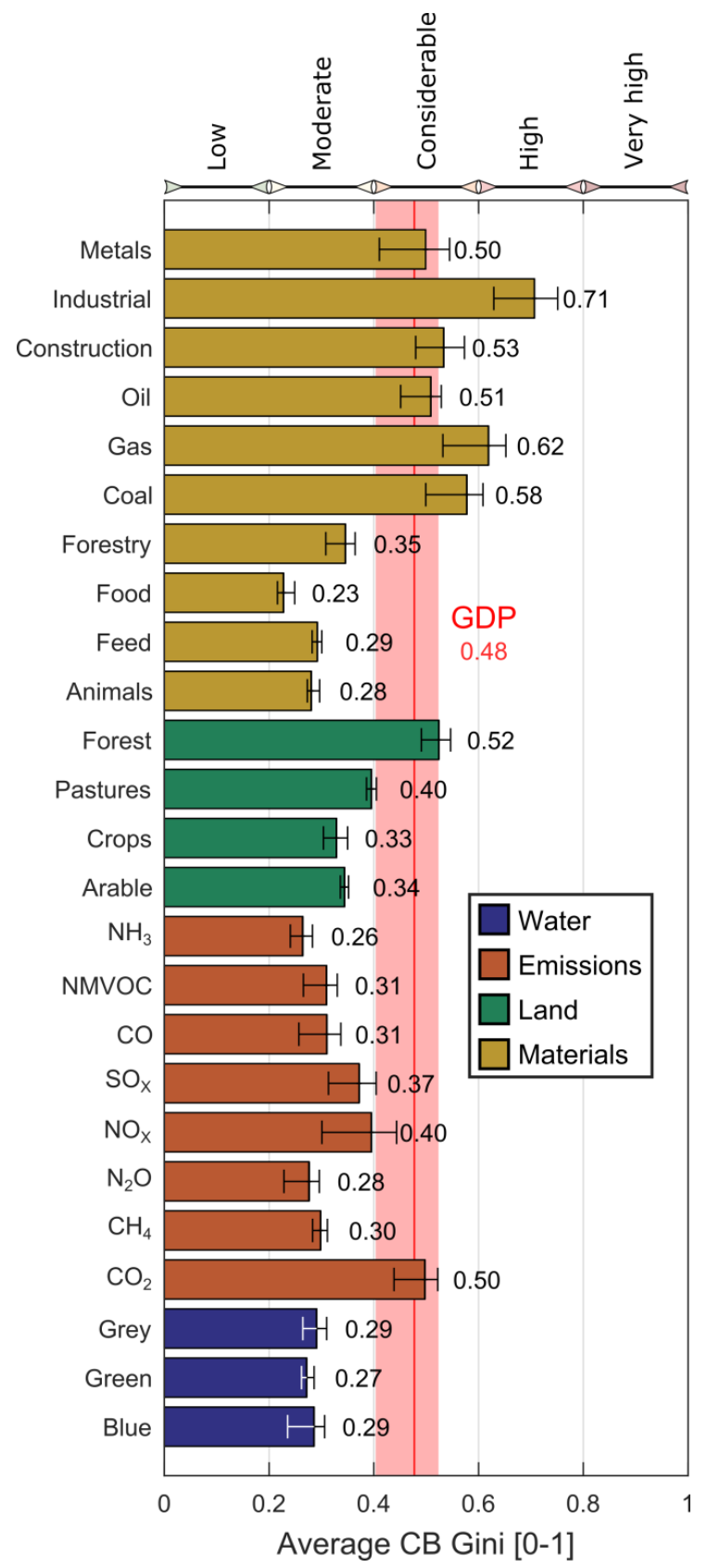

Fig. 1 Assessment of environmental inequality in 1995-2009. Average CB Gini for the 25 environmental burdens (each depicted in a different colour according to the category it belongs to: water, emissions, land and materials). We also show the average economic inequality in the same period (quantified as the Gini coefficient for the GDP at purchasing power parity) as a red line. Error bars show the lowest and highest values for the annual Gini over the period. The horizontal intervals denote the inequality bands, ranging from low $(0 \leq \mathrm{Gini} \leq 0.2)$ to very high $(0.8$ $\leq$ Ginis $\leq 1$ ). NMVOC: non-methane volatile organic compounds. For interpretation of the references to colour, the reader is referred to the web version of this article.

Finally, we identify a set of burdens with high inequality, with Gini values above 0.60 . The first burden in this group is gas, which lies close to other fossil fuels, such as coal (0.62 vs 0.58$)$. These two burdens show larger Ginis than oil, very likely because they are consumed for electricity and heat generation where their share varies greatly across countries. In contrast, oil is used predominantly for producing liquid fuels in transportation. The highest Gini among all the burdens $(0.71)$ corresponds to 
industrial minerals. This burden generated in the secondary sector would be expected to fall in the same inequality band (considerable) as other materials, such as construction and metals. However, it shows a high Gini most likely due to the fact that western countries - mainly EU and USA - consume much more per-capita of industrial minerals than the rest of the world (Supplementary Fig. 1).

Our results show that inequality levels, as well as the role played in satisfying basic needs, vary greatly across burdens. Unlike economic inequality, lowering the $\mathrm{CB}$ burdens inequality does not necessarily imply moving towards sustainability. Indeed, inequality could also be reduced even if all countries increased their emissions and resource usage. Moreover, inequality has different implications depending on the type of burden, such as resource-based indicators (e.g. mineral, water use or land use) vs pollution-based indicators (e.g. $\mathrm{CO}_{2}, \mathrm{NMVOC}$ ). This suggests that tailored policies would be required for each burden, considering its importance and particular characteristics.

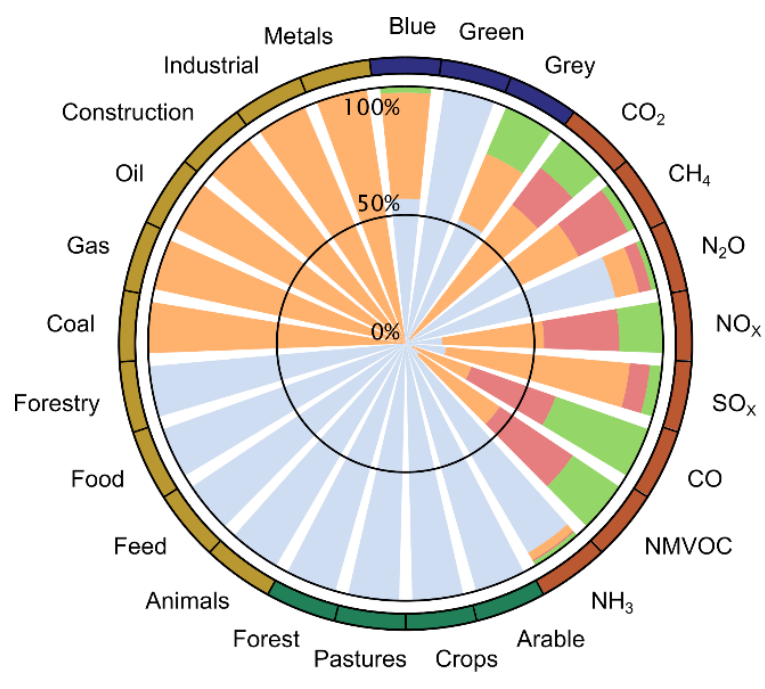

Primary $\bigcirc$ secondary $\bigcirc$ Tertiary $\bigcirc$ Households

Fig. 2 Environmental burdens by economic sector. Each slice corresponds to one environmental burden and shows the yearly average breakdown of the economic sectors generating the burden (i.e. primary, secondary, tertiary and households). The colour of the outermost ring denotes the environmental category of the burden (i.e. water, emissions, land and materials). For interpretation of the references to colour, the reader is referred to the web version of this article.

\subsection{Trends and drivers of environmental inequality}

After analysing international distribution of the burdens, we next study the temporal evolution of their inequality levels from 1995 to 2009 (Fig. 3). This analysis allows us to understand the ongoing trends and major driving forces behind them, to ultimately assess the level of urgency in tackling inequality and how to do it more effectively. Average annual rates in Gini changes are found to range from $-2.71 \%$ to $+0.90 \%$, where negative values reflect a reduction in inequality and positive the converse. The Gini values for most burdens decreased over this period, indicating a trend towards greater equality. At the same time, the GDP Gini also decreased by $-1.83 \%$, evidencing a move towards higher economic equality across countries. Inequality worsened in only three burdens, green and grey water as well as food, all three related to basic human needs, with their Ginis displaying an average growth of $+0.05 \%,+0.90 \%$ and $+0.71 \%$ per year, respectively.

These temporal trends are the external manifestation of several underlying mechanisms affecting inequality. To shed light on these drivers of inequality, we quantify the contribution of four factors towards the Gini variations, each of which could potentially increase or decrease inequality (Fig. 3B): (1) demographic: population size; (2) economic: size and structure of economies; (3) technological: burden intensity, i.e. total burden generated per unit of economic output produced in an economic activity; and (4) household factors: domestic burdens from households resulting from their consumption patterns/lifestyles. The selection of factors (1)-(3) is inspired by the previouslymentioned IPAT expression. Furthermore, factor (4) is consistent with the structure of the MREEIO data (Feng et al., 2015; Guan et al., 2008), where household burdens are modelled as an additional 
factor not linked explicitly to any economic sector. For further details on these factors, see Methods and section 2.3 in the Supplementary Material, where their contribution to the total generation of burdens is also provided (i.e. the vertical dimension, see Supplementary Fig. 2).

According to our analysis, demographic and technological factors contributed to an increase in inequality over the period 1995-2009. In contrast, economic factors pulled in the opposite direction, counterbalancing the first two factors in most of the burdens. The effect of households was weak, contributing towards lower inequality mainly in burdens with large contributions from this sector (grey water, $\mathrm{CO}_{2}, \mathrm{NO}_{X}, \mathrm{CO}$ and $\mathrm{NMVOC}$ ).

To get an insight into why these drivers affected inequality in this way, we study how they evolved in the same time period. Considering first the economic driver, we find that it acted to decrease inequality because emerging economies experienced faster economic growth and a general move from activities in the primary sector to others (often more polluting) in the secondary sector. Hence, economic changes narrowed the gap in per-capita burdens between developing and developed nations. On the downside, they also led to larger global levels of consumption and pollution, thereby damaging the vertical dimension of sustainability (Feng et al., 2015; Guan et al., 2008; Rosa and Dietz, 2012) (Supplementary Fig. 2).

In contrast, the demographic driver contributed to a rise in inequality as population grew faster in developing countries, thereby diluting the increase in per-capita burdens driven jointly by higher economic growth and a transition from primary to secondary activities. Thus, under the ceteris paribus conditions, changes in population would have widened the gap in the per-capita burdens while increasing burdens globally (i.e. more population leads to higher consumption), thereby damaging both sustainability dimensions simultaneously.

Similar to the previous factor, the technological driver also contributed to increase inequality. This happened because developing countries, displaying lower per-capita CB burdens, achieved higher reductions in burden intensity compared to developed ones, where there was less room for improvement. These efficiency improvements were accomplished by adopting better technology and enforcing more stringent regulations. Therefore, under the ceteris paribus conditions, this driver would have also widened disparities across countries while at the same time contributing to curb burdens globally (Supplementary Fig. 2). Note that here we consider countries with quite different socioeconomic status. This has strong implications for the interpretation of the results, as technological changes, despite lowering the total burdens, can adversely affect global inequality as discussed further below.

Finally, households played a minor role, contributing to reduce inequality marginally, particularly in burdens such as grey water, $\mathrm{CO}_{2}, \mathrm{NO}, \mathrm{CO}$ and $\mathrm{NMVOC}$ emissions. This could be attributed to the faster growth of private transport and urbanisation experienced in developing countries. Again, as with population, this factor helped to reduce inequality but increased total burdens, thus affecting the two sustainability dimensions in opposite directions.

These results, therefore, highlight the need to consider the horizontal and vertical dimensions of sustainability simultaneously to help identify and address the trade-offs between them.

\subsection{Regional contributors to inequality}

To understand further how inequality in the burdens' distribution emerges and which regions contribute the most to its global level, we next analyse the regional breakdown of Ginis in 1995-2009 (see Fig. 4A and Methods). We find that inequality is mainly due to few highly populated countries, namely China, India and the USA. These three countries, altogether representing on average $42 \%$ of the world population over the same period, displayed average contributions towards the Gini ranging from $37 \%$ for industrial minerals to $51 \%$ for construction minerals. For instance, in animal feed, denoting the amount of food fed to farm animals, $42 \%$ of the Gini value was due to China (17\%), India $(15 \%)$ and the USA (10\%). This is despite the significant differences in this burden between China and India ( 0.8 and $0.7 \mathrm{t} /$ cap, respectively) compared to the USA ( $3 \mathrm{t} / \mathrm{cap})$. On the other hand, the region labelled as rest of the world (RoW), accounting for $34 \%$ of the world population, was responsible for proportionally less of the same Gini (23\%). 

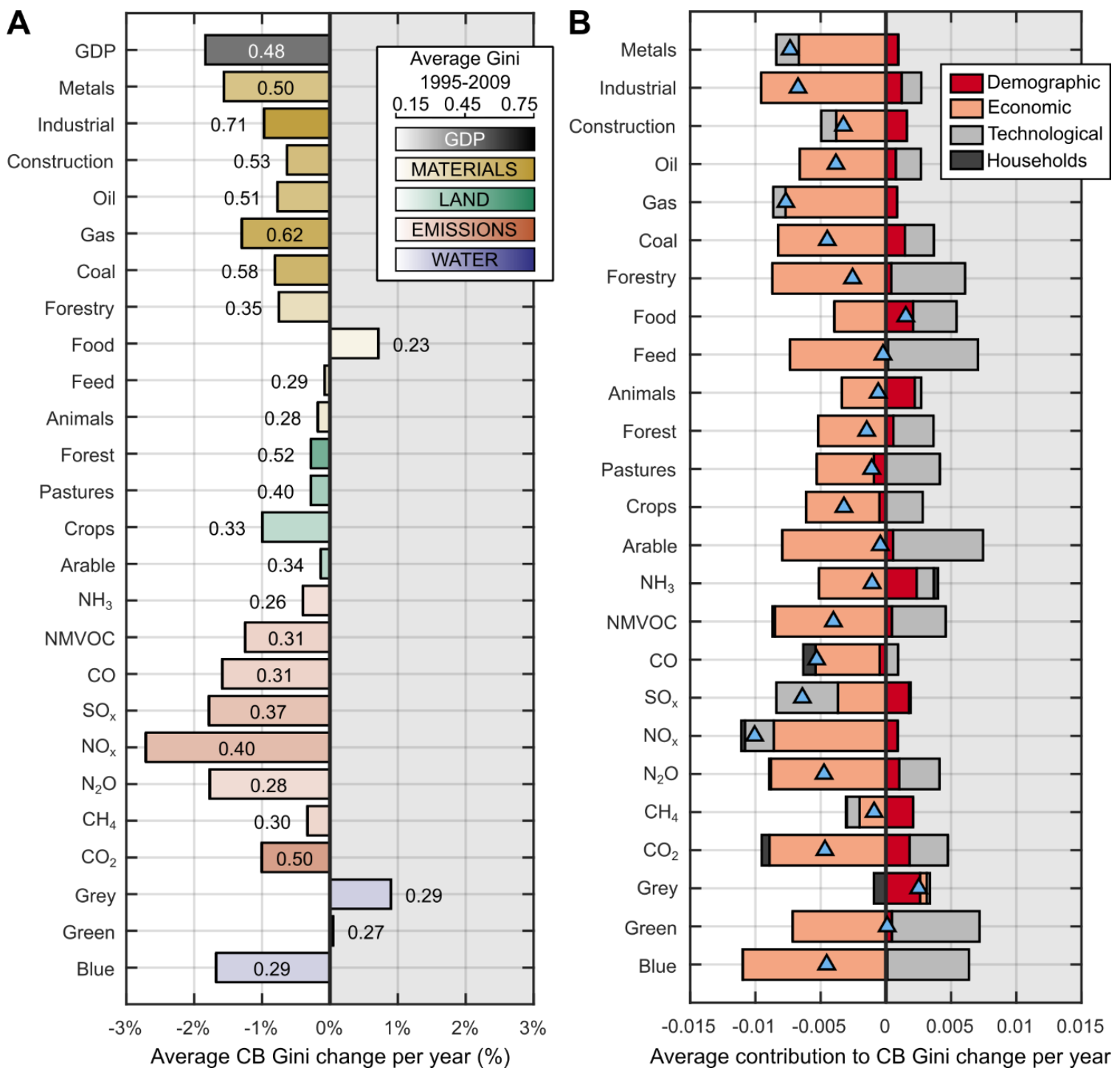

Fig. 3 Analysis of trends and drivers of Ginis for the period 1995-2009. A Change in CB Gini. For each burden, the length of the bar denotes the average annual change in the CB Gini over the period 1995-2009. The colour gradient indicates the average CB Gini for the same period. Bar colours denote the four indicator categories (i.e. materials, land, emissions and water) together with the GDP. B Drivers of change in Gini. For each burden, we show the average contribution of the four factors to the annual changes in Gini in 1995-2009. Blue triangles indicate the average change in inequality within the period 1995-2009. The shaded region on the right-hand side of both subplots represents a trend towards higher inequality levels. For interpretation of the references to colour, the reader is referred to the web version of this article.

Furthermore, significant changes in per-capita burdens can occur regionally even when the Gini remains almost constant (Lorenz curves (Allison, 1978; Lorenz, 1905) in Figs. 4B and 4C). Indeed, the feed Gini decreased marginally from 0.30 in 1995 to 0.29 in 2009, yet there were substantial changes in the ranking of countries in terms of per-capita burden generation. Notably, Lithuania and Slovakia moved 19 and 11 positions upwards, respectively, while Japan dropped 16 places, and Taiwan and the RoW eight. Moreover, the difference between the largest and lowest per-capita burden generation among countries (maximum disparity) increased from $10.3 \mathrm{t} / \mathrm{cap}$ in 1995 (10.8 t/cap in Australia compared to $0.5 \mathrm{t} /$ cap in Indonesia) to $10.5 \mathrm{t} /$ cap in 2009 (11.0 t/cap compared to $0.4 \mathrm{t} / \mathrm{cap}$ in the same countries). Additionally, the total burden generated grew from $8.2 \mathrm{t}$ in 1995 to $9 \mathrm{t}$ in 2009, thereby exerting more pressure on a planet with limited resources (Venter et al., 2016). 

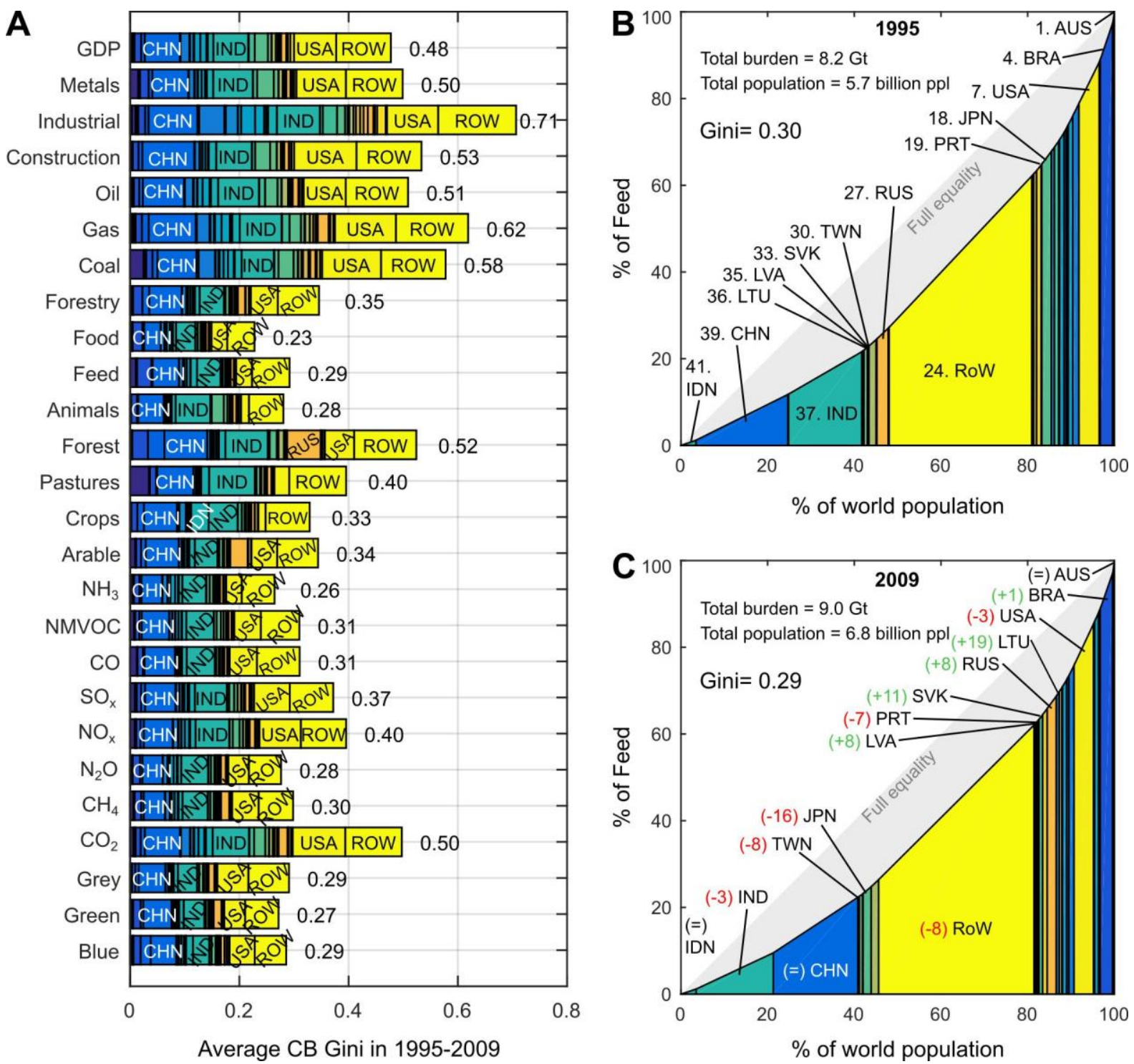

Fig. 4 Regional implications of inequality. A Average regional contribution to inequality in 1995-2009. The figure shows the average annual contribution of each region to the consumption-based Ginis over the period 19952009. Each region is shown in a different colour and only those with a contribution above $10 \%$ are labelled. Average consumption-based Gini values are depicted next to each bar. B and C Lorenz curves (cumulative distribution of burden, where countries are ranked according to their per-capita consumption-based burden) for feed for 1995 and 2009, respectively. In B, labels indicate the region and its ranking in terms of per-capita consumption-based burden. In C, the change in ranking for per-capita burdens between 1995 and 2009 is shown in parenthesis, where red denotes a decrease and green an increase in the ranking. For interpretation of the references to colour, the reader is referred to the web version of this article.

These results evidence that monitoring only an aggregated inequality indicator like the Gini might be insufficient when attempting to measure progress towards an equality goal. Hence, both the specific disparities across countries and the total amount of global burden generated should be considered concurrently in any sustainability study (Cobham, 2013; Engberg-Pedersen, 2013; Palma, 2011, 2006).

\subsection{Towards regional roadmaps: implementation and monitoring}

We finally envision a comprehensive framework to tackle inequality more effectively based on our results. Pursuing the goal of distributing burdens more equitably through a long-term strategy, we discuss how to articulate international regulations and underpin potential negotiations using analytical tools. We propose that the first step should involve the definition of quantitative goals reflecting maximum allowable levels of inequality that should not be exceeded. This is a controversial topic 
never addressed in depth by any organisation, including the UN, which stopped short of setting economic or social equality targets in its 2030 Agenda and instead relied on alternative control variables, such as income growth or remittance costs (United Nations, 2015a). Recognising that full equality (i.e. zero Gini) can be detrimental for economic growth and social stability (Hollanders, 2015), we propose a general roadmap towards environmental equality based on decreasing the Gini values by a certain percentage $(\rho)$ over an $x$-years policy horizon, subject to periodic revision over time. We argue that this percentage $\rho$ should be established according to a priority level, defined considering qualitative criteria. We propose two such criteria: (i) the type of environmental burden, i.e. mostly linked to either basic human needs, comforts or luxuries; and (ii) its current level of inequality as given by the five bands defined previously (see Fig. 1).

Following this approach, we introduce a barometer where the burdens related to basic human needs and currently showing higher Ginis would be given higher priority and, therefore, larger $\rho$ values (Fig. 5). As an example, distributing consumption of some metals fairly might be less critical than ensuring a fair distribution in food (Lu et al., 2015; Wood et al., 2018). In practice, grouping burdens into categories following criterion (i) would require a detailed analysis of their roles in the global economy to produce a fair and coherent taxonomy. Other additional principles could also be added in the barometer, such as the extent to which the burdens are connected to critical environmental impacts for which action is most urgently needed. The use of a barometer, regardless of the type of criteria agreed, would provide a consistent framework to translate qualitative criteria into quantitative limits, as required for an effective monitoring and control of inequality.

Overall, it is apparent that establishing targets for reducing inequality will require some subjective decisions and articulation of preferences (Van der Veen, 2003) and it should ultimately be a political decision (Engberg-Pedersen, 2013; Fukuda-Parr et al., 2014). However, the use of criteria like (i) and (ii) could facilitate a consensus among stakeholders with different and often conflicting interests. In this context, our barometer could, therefore, help to establish more effective targets and make betterinformed policy decisions.

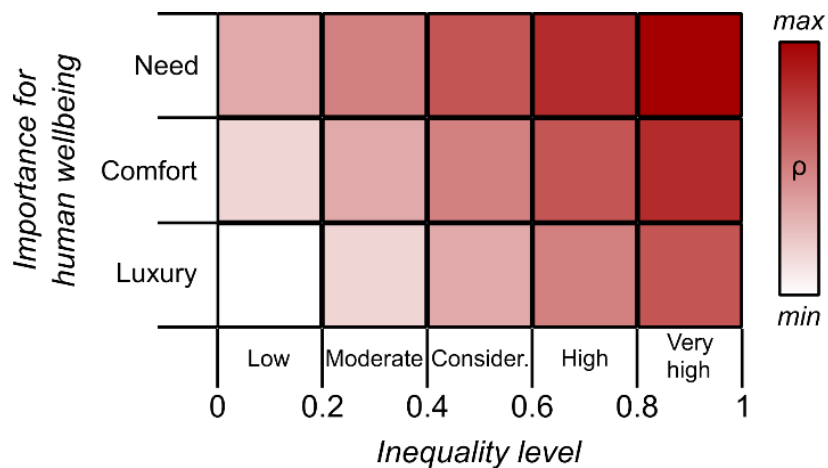

Fig. 5 Barometer for establishing reduction targets for global Ginis according to the priority level of the burden. The rows classify indicators according to their role in satisfying human needs, whereas the columns reflect their current inequality level.

Ensuring a stand-alone Gini target might be insufficient to reduce effectively global inequality since, as already discussed, burden distributions entailing different maximum disparities can lead to similar Gini values. Therefore, quotas will need to be imposed by region considering maximum disparities between them to ultimately succeed in reducing inequality more effectively. Furthermore, translating inequality targets into regional quotas (i.e. maximum CB per-capita burdens) is not straightforward, since the same inequality level could be ensured in multiple alternative ways, each affecting every region differently. While some sharing principles are being discussed for establishing quotas on greenhouse gas emissions (Chakravarty et al., 2009; Höhne et al., 2014; Raupach et al., 2014; Ringius et al., 2002), these do not allow to enforce explicitly a given bound on inequality or accommodate easily specific optimality criteria when performing the burdens allocation.

To circumvent these limitations and provide more flexibility when allocating burdens, we apply systems optimisation to this problem. Following this approach, we formulate a mathematical model that seeks optimal per-capita CB burdens satisfying limits on inter-country disparities, on the Gini 
coefficient (horizontal dimension of sustainability) and on the total amount of burdens generated (vertical dimension of sustainability); for details, see Methods.

We then apply our approach to allocate quotas on $\mathrm{CO}_{2}$ as an illustrative case; an additional case considering blue water is discussed in section 1.3 and Fig. 3 in the Supplementary Material. To this end, using our barometer, an exemplifying Gini reduction target $\rho$ of $20 \%$ is set, i.e. a burden related to comfort and with considerable inequality in 2009. While the target considered here is chosen arbitrarily for illustration purposes only, in practice environmental equality targets could be agreed by an international panel of experts and policy makers taking into account the specific role of each burden in ensuring human wellbeing and its current inequality level. The target sought should be for the year 2030, the time horizon for the Sustainable Development Goals, taking 2009 as the reference year. Moreover, the maximum disparity should drop by $20 \%$ compared to 2009 levels (i.e. the same reduction as for the Gini), while imposing a limit on the total $\mathrm{CO}_{2}$ released of $11.24 \mathrm{Gt} \mathrm{CO}_{2} / \mathrm{yr}$. The latter is consistent with the planetary boundary of approximately $1,000 \mathrm{Gt}$ of cumulative $\mathrm{CO}_{2}$ allowed between 2011 to 2100 for a "high" probability $(66 \%)$ of achieving the $2^{\circ} \mathrm{C}$ temperature goal of the Paris Agreement (UNFCCC, 2015), distributed uniformly over the years (O'Neill et al., 2018). The optimisation model seeks to deviate the minimum from the current distribution of burdens while at the same time not surpassing the inequality target sought.

For the values defined above, the optimal solution (Fig. 6) entails curbing the per-capita $\mathrm{CB} \mathrm{CO}_{2}$ emissions of 14 regions, while keeping emissions unaltered in the remaining countries (depicted in grey in the figure). These targeted regions were responsible for $89 \%$ of the global emissions in 2009 , a percentage share that would drop to $68 \%$ after meeting the 2030 targets. Seven regions would require reductions above $90 \%$ in per-capita emissions: the USA, Canada, Germany, the UK, Japan, Australia and Russia. For others, these reductions would be more modest, but still significant: between $50 \%$ and $90 \%$ in China, RoW and France and below $50 \%$ in India, South Korea, Italy and Mexico. These targets would make the Gini drop from 0.44 to 0.35 , while decreasing the maximum disparity from 19,595 to $15,187 \mathrm{kt} \mathrm{CO}_{2} / \mathrm{cap}$. The world average per-capita emissions would be reduced by $69 \%$ (from $4,231 \mathrm{kt} \mathrm{CO} / \mathrm{cap}$ in 2009 to $1,314 \mathrm{kt} \mathrm{CO} /$ cap in 2030), thereby curbing total $\mathrm{CO}_{2}$ emissions by $61 \%$ (from 28,85 to $11,24 \mathrm{Gt} \mathrm{CO}_{2} / \mathrm{yr}$ ) despite an expected population growth of $25.4 \%$ in 2030 compared to 2009. Hence, emission targets focused on some countries would avoid transgressing the planetary boundary in climate change, while meeting the equality goals effectively.

After agreeing on the national quotas provided by the model, nations and governments should put them into practice via regulations and policy instruments, including consumer-oriented pricing schemes (Ottelin et al., 2019). With regard to $\mathrm{CO}_{2}$ emissions, a wide range of abatement opportunities would be available for the countries to meet their quotas. In countries where $\mathrm{CO}_{2}$ emissions come mostly from the sector Electricity, Gas and Water Supply (e.g. 34\% in the USA and $45 \%$ in China), decarbonisation and deployment of $\mathrm{CO}_{2}$ removal technologies could play a major role in meeting the targets (Smith et al., 2016). In other countries with low-carbon electricity, such as Japan, Canada and France, but with high households emissions (12\%, 16\% and 23\% respectively), greener transport, better building insulation in the residential sector and behavioural actions should be the focus of regulations (Dietz et al., 2009; Jones and Kammen, 2011).

When delineating mitigation options, imported burdens should also be considered as they can be large, particularly in countries moving most of their manufacturing facilities overseas (Dalin et al., 2017; Davis et al., 2011; Peters et al., 2011). For example, $45 \%$ of the total $\mathrm{CB}^{\mathrm{CO}} \mathrm{C}_{2}$ emissions in France are embodied in its imports (Davis et al., 2011). In this regard, technology transfers from the developed to the developing countries should be encouraged; for instance, similar to the Kyoto's Clean Development Mechanism (Heil and Wodon, 1997; Shan et al., 2018).

\section{Discussion}

The implications of our results for policy-making are diverse. The disparities in inequality levels across burdens with different roles in ensuring well-being call for tailored regulations setting specific safety limits for each of them. In controlling inequality, burdens related to basic human needs should be prioritised, as inequalities in their distribution might trigger social conflicts (Anonymous, 2018a). This might be more critical in resources with shrinking availability, potentially facing undersupply. As an example, consider the Arab Spring, regarded as a "revolution of the hungry" that, arguably, could have been prevented by avoiding food shortages (UNESCO, ISSC and IDS, 2016). 


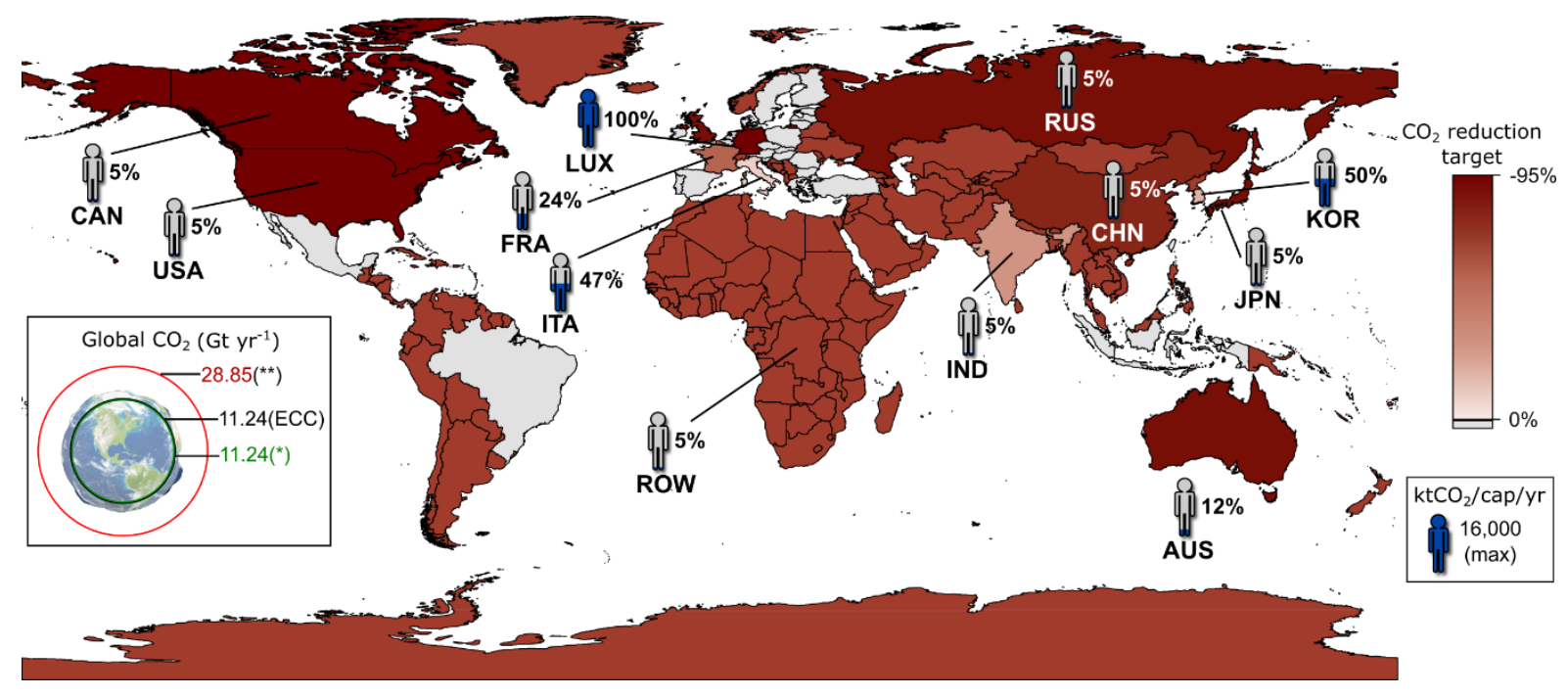

Fig. 6 Region specific targets proposed for 2030 on the per-capita consumption-based $\mathrm{CO}_{2}$ emissions. Countries are coloured according to the proposed target, expressed as the reduction required in their consumption-based $\mathrm{CO}_{2}$ emissions with respect to their 2009 levels (e.g. Russia would need to curb their emissions by $90 \%$ compared to the 2009 levels). These targets can be translated into the corresponding amount of per-capita consumption-based $\mathrm{CO}_{2}$ emissions allowed in each country, as given within the silhouette of a person and expressed as a percentage of the emissions of the country for which this value is the highest (i.e. Luxembourg, standing at $16,000 \mathrm{kt} \mathrm{CO} / \mathrm{cap}$, corresponds to $100 \%$ ). The global $\mathrm{CO}_{2}$ emissions ( $\mathrm{Gt}_{\mathrm{CO}} / \mathrm{yr}$ ) are given in the planet legend, which shows the Earth's carrying capacity (ECC), the current $\mathrm{CO}_{2}$ emissions in $2009\left(^{* *}\right)$ and those resulting from the $2030\left(^{*}\right)$ targets. For interpretation of the references to colour, the reader is referred to the web version of this article.

The temporal analysis of environmental inequality between 1995-2009 revealed a general slow trend towards greater equality. Despite this, inequality grew in burdens related to the basic needs, such as green and grey water as well as food, which is a matter of concern considering their future potential scarcity (Anonymous, 2018b). Hence, international action and new approaches are urgently needed to ensure a sustainable future: short and long-term regulations and policies should be developed and enforced now to accelerate the general decline in inequality to ultimately keep it within allowable limits.

We found that global inequality is largely caused by a handful of highly-populated countries that should be targeted first when attempting to keep inequality low. Changes in population and technology efficiency were found to be the main drivers of inequality, while changes in the size and structure of the world economies counterbalanced them, thereby leading to a global decline in inequality between 1995 and 2009. The analysis of these drivers revealed the existence of a trade-off between lowering the inequality and reducing total burdens, which is inherent to driving forces showing opposite contributions towards the horizontal and vertical dimensions of sustainability. Population growth in emerging economies, on the contrary, damaged both sustainability dimensions (Bradshaw and Brook, 2014; Ehrlich et al., 2012) and it might continue to do so if the current population trends persist. As policies for controlling population are controversial and largely ineffective, other options for addressing inequality need to be considered instead. Of the four factors studied here, this then leaves the households and technology as possible targets.

Technology advances should focus on reducing burdens connected to the most critical impacts, such as $\mathrm{CO}_{2}$, linked to climate change, which in turn threatens agricultural productivity worldwide (Stevanović et al., 2016). The constant drive towards increasing the GDP growth, already a subject of intense debate (Robert et al., 2014), might inevitably lead us to the transgression of planetary boundaries. For the most critical burdens, regional quotas will need to be defined and, in doing so, a range of criteria and sharing principles will have to be explored, including equality goals. Hence, technology will need to be developed and transferred to the right locations to help us operate below those quotas with a minimum negative impact on the economy. In this process, it might also be necessary to trade products and knowledge and promote foreign investment and mobility of skilled workforce (Heil and Wodon, 1997). If these actions succeed in operating safely within the Earth's 
ecological limits, it is likely that the horizontal dimension of sustainability will become less relevant; yet, ensuring fairness in the distribution of burdens will always matter as it reflects the universal goal of environmental justice.

We envisioned a roadmap to tackle inequality more effectively based on setting specific targets and translating them into $\mathrm{CB}$ quotas via systems optimisation. The use of $\mathrm{CB}$ accounting, requiring production-based data together with data on imports, exports and demands, which might be hard to gather, will be challenging by itself. As a starting point to develop robust policy instruments, international acceptance and statistics for international trade and CB inventories would need to be overseen and monitored, as suggested in previous works (Duus-Otterström and Hjorthen, 2019; Peters et al., 2011). Furthermore, enforcing CB quotas would require consumer-oriented interventions, including pricing schemes. Moreover, trade-related mechanisms could also be established to enforce these quotas (e.g. border burden adjustments via taxes), which would require deep international coordination and cooperation (He and Hertwich, 2019). In any case, our conceptual framework is flexible and could, therefore, be taken as a starting point for other approaches making explicit links between burdens generation and planetary boundaries, both global and regional. Potential areas for improvement include tailored optimisation models for each particular burden, the incorporation of abatement costs or international cooperation considerations to meet targets more effectively (Chakravarty et al., 2009; Dawes et al., 2007; Galán-Martín et al., 2018; Raupach et al., 2014).

Pursuing a more equitable future is not a one-time task, but rather a continuing one: inequality targets should be reviewed periodically to accommodate trends following long-term strategies, which will likely pose challenges for accounting and governance (Jakob et al., 2014; Wiedmann and Lenzen, 2018). Regional quotas could thus be recalculated using updated inputs to deal with potential disturbances, such as conflicts, financial instabilities and technological breakthroughs. By integrating both the vertical (total burden) and horizontal (burden distribution) sustainability dimensions, the proposed approach would, therefore, help to control and monitor progress towards sustainable development while ensuring a safe operation within both dimensions.

\section{Conclusions}

The inequality debate typically addresses economic and social inequality, while environmental inequality is often omitted. The advent of MREEIO models offers the opportunity to enlarge in scope inequality studies beyond the economic dimension and embrace environmental burdens. We argued here that this is particularly important for at least two reasons. Firstly, following the general goal of pursuing environmental justice, we should ensure fair access to environmental assets and burden generation. Secondly, because the seemingly unstoppable economic growth will likely push us towards the limits of the safe-operation region defined by the planetary boundaries; consequently, quotas on burdens will need to be agreed soon and distributed with fairness to ensure a successful deal.

Developing effective regulations to address inequality in the burdens' distribution will require a deeper and broader knowledge on environmental inequality, its sources and driving forces. Capitalising on the findings of this work and considering that no quantitative inequality targets are at present available, we advocate the establishment of a roadmap towards environmental equality based on accomplishing successive reductions in Ginis over time, that could be explicitly defined using the barometer proposed here. This barometer translates qualitative criteria into quantitative targets, allowing for the inclusion of additional aspects of the inequality problem relevant to different stakeholders and policy makers. Then, inequality targets would be subsequently translated into regional quotas on burdens via systems optimisation, ensuring simultaneously the fulfilment of inequality limits and a safe operation below the Earth's carrying capacity.

Overall, our helps to improve currently limited knowledge of environmental inequality and showcases the capabilities of systems approaches in providing integral solutions towards sustainable development. It is hoped that this work will trigger further discussion on the need to address environmental inequality, currently missing in the Sustainable Development Goals, and open up new research avenues on the use of systems approaches in solving global sustainability problems. 
Data statement

The data that support the findings of this study are available from the corresponding authors upon reasonable request.

\section{Code statement}

The computer codes used for this study are available from the corresponding authors upon reasonable request.

\section{Acknowledgements}

G.GG thanks the Spanish Ministry of Education and Competitiveness (CTQ2016-77968-C3-1-P, MINECO/FEDER) for the financial support received. C.P and G.GG thank the financial support from NERC - Natural Environment Research Council (PSD202). R.G. and M.SP acknowledge the support of the Spanish Ministry of Education and Competitiveness (FIS2016-78904-C3-1-P ). A.A would like to thank the UK Engineering and Physical Sciences Research Council, EPSRC (Grant no. EP/F007132/1).

\section{References}

Al-Iriani, M.A., 2006. Energy--GDP relationship revisited: an example from GCC countries using panel causality. Energy Policy 34, 3342-3350.

Alesina, A., Perotti, R., 1996. Income distribution, political instability, and investment. Eur. Econ. Rev. 40, 1203-1228.

Allison, P.D., 1978. Measures of inequality. Am. Sociol. Rev. 865-880.

Anonymous, 2018a. Brazil's sustainability needs social sciences. Nat. Sustain. 1, 607. https://doi.org/10.1038/s41893-018-0183-0.

Anonymous, 2018b. Sustainable agriculture. Nat. Sustain. 1, 531. https://doi.org/10.1038/s41893-0180163-4.

Apergis, N., Payne, J.E., 2010. The emissions, energy consumption, and growth nexus: evidence from the commonwealth of independent states. Energy Policy 38, 650-655.

Biewen, M., 2012. Additive decompositions with interaction effects. IZA Discuss. Pap. No. 6730.

Biewen, M., 2014. A general decomposition formula with interaction effects. Appl. Econ. Lett. 21, 636-642. https://doi.org/10.1080/13504851.2013.879280

Birdsall, N., 2002. Asymmetric globalization: global markets require good global politics.

Bourguignon, F., 2004. The poverty-growth-inequality triangle. Poverty, Inequal. Growth 69, 69-73.

Boyce, J.K., Zwickl, K., Ash, M., 2016. Measuring environmental inequality. Ecol. Econ. 124, 114123. https://doi.org/10.1016/j.ecolecon.2016.01.014

Bradshaw, C.J.A., Brook, B.W., 2014. Human population reduction is not a quick fix for environmental problems. Proc. Natl. Acad. Sci. 111, 16610-16615.

Campbell, C., 1998. Consumption and the Rhetorics of Need and Want. J. Des. Hist. 11, 235-246.

Chakravarty, S., Chikkatur, A., de Coninck, H., Pacala, S., Socolow, R., Tavoni, M., 2009. Sharing global $\mathrm{CO}_{2}$ emission reductions among one billion high emitters. Proc. Natl. Acad. Sci. U. S. A. 106, 11884-8. https://doi.org/10.1073/pnas.0905232106.

Cingano, F., 2014. Trends in Income Inequality and its Impact on Economic Growth. https://doi.org/https://doi.org/http://dx.doi.org/10.1787/5jxrjncwxv6j-en

Cobham, A., 2013. Palma vs. Gini: Measuring Post-2015 Inequality. Cent. Glob. Dev. Blog 4.

Dalin, C., Wada, Y., Kastner, T., Puma, M.J., 2017. Groundwater depletion embedded in international food trade. Nature 543, 700.

Davis, S.J., Caldeira, K., 2010. Consumption-based accounting of $\mathrm{CO}_{2}$ emissions. Proc. Natl. Acad. Sci. U. S. A. 107, 5687-92. https://doi.org/10.1073/pnas.0906974107

Davis, S.J., Peters, G.P., Caldeira, K., 2011. The supply chain of $\mathrm{CO}_{2}$ emissions. Proc. Natl. Acad. Sci. U. S. A. 108, 18554-9. https://doi.org/10.1073/pnas.1107409108

Dawes, C.T., Fowler, J.H., Johnson, T., McElreath, R., Smirnov, O., 2007. Egalitarian motives in humans. Nature 446, 794.

Dietz, T., Gardner, G.T., Gilligan, J., Stern, P.C., Vandenbergh, M.P., 2009. Household actions can provide a behavioral wedge to rapidly reduce US carbon emissions. Proc. Natl. Acad. Sci. 106, 18452-18456.

Dietzenbacher, E., Los, B., Stehrer, R., Timmer, M., De Vries, G., 2013. The construction of world input-output tables in the WIOD project. Econ. Syst. Res. 25, 71-98.

Dorfman, R., 1979. A Formula for the Gini Coefficient. Rev. Econ. Stat. 61, 146-49.

Duro, J.A., Padilla, E., 2006. International inequalities in per capita $\mathrm{CO}_{2}$ emissions: a decomposition 
methodology by Kaya factors. Energy Econ. 28, 170-187.

Duro, J.A., Teixidó-Figueras, J., 2013. Ecological footprint inequality across countries: The role of environment intensity, income and interaction effects. Ecol. Econ. 93, 34-41. https://doi.org/10.1016/j.ecolecon.2013.04.011

Duus-Otterström, G., Hjorthen, F.D., 2019. Consumption-based emissions accounting: the normative debate. Env. Polit. 28, 866-885.

Easterly, W., Ritzen, J., Woolcock, M., 2006. Social cohesion, institutions, and growth. Econ. Polit. 18, 103-120.

Ehrlich, P.R., Kareiva, P.M., Daily, G.C., 2012. Securing natural capital and expanding equity to rescale civilization. Nature 486, 68-73.

Engberg-Pedersen, L., 2013. Development goals post 2015: Reduce inequality. DIIS.

European Commission, 2017. CAP context indicators 2014-2020 Annexes.

Feng, K., Davis, S.J., Sun, L., Hubacek, K., 2015. Drivers of the US $\mathrm{CO}_{2}$ emissions 1997-2013. Nat. Commun. 6, 7714.

Fukuda-Parr, S., Yamin, A.E., Greenstein, J., 2014. The power of numbers: a critical review of millennium development goal targets for human development and human rights. J. Hum. Dev. Capab. 15, 105-117.

Galán-Martín, A., Pozo, C., Azapagic, A., Grossmann, I.E., Mac Dowell, N., Guillén-Gosálbez, G., 2018. Time for global action: an optimised cooperative approach towards effective climate change mitigation. Energy Environ. Sci. 11(3) 572-581.

Griggs, D., Stafford-Smith, M., Gaffney, O., Rockström, J., Öhman, M.C., Shyamsundar, P., Steffen, W., Glaser, G., Kanie, N., Noble, I., 2013. Policy: Sustainable development goals for people and planet. Nature 495, 305-307.

Griggs, D., Stafford Smith, M., Rockström, J., Öhman, M.C., Gaffney, O., Glaser, G., Kanie, N., Noble, I., Steffen, W., Shyamsundar, P., 2014. An integrated framework for sustainable development goals.

Guan, D., Hubacek, K., Weber, C.L., Peters, G.P., Reiner, D.M., 2008. The drivers of Chinese $\mathrm{CO}_{2}$ emissions from 1980 to 2030. Glob. Environ. Chang. 18, 626-634.

He, K., Hertwich, E.G., 2019. The flow of embodied carbon through the economies of China, the European Union, and the United States. Resour. Conserv. Recycl. 145 190-198. https://doi.org/10.1016/j.resconrec.2019.02.016

Hedenus, F., Azar, C., 2005. Estimates of trends in global income and resource inequalities. Ecol. Econ. 55, 351-364.

Heil, M.T., Wodon, Q.T., 2000. Future inequality in $\mathrm{CO}_{2}$ emissions and the impact of abatement proposals. Environ. Resour. Econ. 17, 163-181.

Heil, M.T., Wodon, Q.T., 1997. Inequality in $\mathrm{CO}_{2}$ emissions between poor and rich countries. J. Environ. Dev. 6, 426-452.

Hoekstra, A.Y., Wiedmann, T.O., 2014. Humanity's unsustainable environmental footprint. Science 344, 1114-7. https://doi.org/10.1126/science.1248365

Höhne, N., den Elzen, M., Escalante, D., 2014. Regional GHG reduction targets based on effort sharing: a comparison of studies 14, 122-147. https://doi.org/10.1080/14693062.2014.849452

Hollanders, D., 2015. The Great Divide: Unequal Societies and What We Can Do about Them.

International Monetary Fund (2011). World Economic Outlook. https://www.imf.org/external/pubs/ft/weo/2011/02/weodata/download.aspx (accessed 7.6.17).

Jackson, T., 2005. Motivating sustainable consumption. Sustain. Dev. Res. Netw. 29, 30.

Jakob, M., Steckel, J.C., Edenhofer, O., 2014. Consumption-versus production-based emission policies. Annu. Rev. Resour. Econ. 6, 297-318.

Jelin, E., Motta, R., Costa, S., 2017. Global Entangled Inequalities: Conceptual Debates and Evidence from Latin America. Routledge.

Jones, C.I., 2016. The facts of economic growth, in: Handbook of Macroeconomics. Elsevier, pp. 369.

Jones, C.M., Kammen, D.M., 2011. Quantifying carbon footprint reduction opportunities for US households and communities. Environ. Sci. Technol. 45, 4088-4095.

Jorgenson, A.K., Fiske, S., Hubacek, K., Li, J., McGovern, T., Rick, T., Schor, J.B., Solecki, W., York, R., Zycherman, A., 2019. Social science perspectives on drivers of and responses to global climate change. Wiley Interdiscip. Rev. Clim. Chang. 10, e554.

Kwakkel, J.H., Timmermans, J.S., 2012. Blue limits of the Blue Planet: an exploratory analysis of safe operating spaces for human water use under deep uncertainty, in: CESUN 2012: 3rd International Engineering Systems Symposium, Delft University of Technology, The 
Netherlands, 18-20 June 2012.

Leach, M., Raworth, K., Rockström, J., 2013. Between social and planetary boundaries: Navigating pathways in the safe and just space for humanity. World Soc. Sci. Rep. 2013, 84-89.

Lim, K.-M., Lim, S.-Y., Yoo, S.-H., 2014. Oil consumption, $\mathrm{CO}_{2}$ emission, and economic growth: evidence from the Philippines. Sustainability 6, 967-979.

Lorenz, M.O., 1905. Methods of Measuring the Concentration of Wealth. Publ. Am. Stat. Assoc. 9, 209-219.

Lu, Y., Jenkins, A., Ferrier, R.C., Bailey, M., Gordon, I.J., Song, S., Huang, J., Jia, S., Zhang, F., Liu, X., 2015. Addressing China's grand challenge of achieving food security while ensuring environmental sustainability. Sci. Adv. 1, e1400039.

Ma, M., Cai, Wei, Cai, Weiguang, Dong, L., 2019. Whether carbon intensity in the commercial building sector decouples from economic development in the service industry? Empirical evidence from the top five urban agglomerations in China. J. Clean. Prod. 222, 193-205. https://doi.org/10.1016/j.jclepro.2019.01.314

Milanovic, B., 2013. Global income inequality in numbers: In history and now. Glob. policy 4, 198208.

Naeem, S., Chazdon, R., Duffy, J.E., Prager, C., Worm, B., 2016. Biodiversity and human well-being: an essential link for sustainable development. Proc. R. Soc. B 283, 20162091.

O'Neill, D.W., Fanning, A.L., Lamb, W.F., Steinberger, J.K., 2018. A good life for all within planetary boundaries. Nat. Sustain. $1,88$.

Ottelin, J., Ala-Mantila, S., Heinonen, J., Wiedmann, T., Clarke, J., Junnila, S., 2019. What can we learn from consumption-based carbon footprints at different spatial scales? Review of policy implications. Environ. Res. Lett. 14, 093001. https://doi.org/10.1088/1748-9326/ab2212

Padilla, E., Serrano, A., 2006. Inequality in $\mathrm{CO}_{2}$ emissions across countries and its relationship with income inequality: A distributive approach. Energy Policy 34, 1762-1772. https://doi.org/10.1016/j.enpol.2004.12.014.

Palma, J.G., 2011. Homogeneous Middles vs. Heterogeneous Tails, and the End of the 'Inverted-U': It's All About the Share of the Rich. Dev. Change 42, 87-153.

Palma, J.G., 2006. Globalizing inequality:'centrifugal'and 'centripetal'forces at work. DESE Working Paper no. 35. New York: UN Department of Economic and Social Affairs.

Pan, X., Teng, F., Ha, Y., Wang, G., 2014. Equitable Access to Sustainable Development: Based on the comparative study of carbon emission rights allocation schemes. Appl. Energy 130, 632640. https://doi.org/10.1016/j.apenergy.2014.03.072

Peters, G.P., Minx, J.C., Weber, C.L., Edenhofer, O., 2011. Growth in emission transfers via international trade from 1990 to 2008. Proc. Natl. Acad. Sci. U. S. A. 108, 8903-8. https://doi.org/10.1073/pnas.1006388108

Qian, Y., Behrens, P., Tukker, A., Rodrigues, J.F.D., Li, P., Scherer, L., 2019. Environmental responsibility for sulfur dioxide emissions and associated biodiversity loss across Chinese provinces. Environ. Pollut. 245, 898-908.

Raupach, M.R., Davis, S.J., Peters, G.P., Andrew, R.M., Canadell, J.G., Ciais, P., Friedlingstein, P., Jotzo, F., van Vuuren, D.P., Le Quere, C., 2014. Sharing a quota on cumulative carbon emissions. Nat. Clim. Chang. 4, 873-879.

Ridgeway, C.L., 2011. Framed by gender: How gender inequality persists in the modern world. Oxford University Press.

Ringius, L., Torvanger, A., Underdal, A., 2002. Burden Sharing and Fairness Principles in International Climate Policy. Int. Environ. Agreements 2, 1-22. https://doi.org/10.1023/A:1015041613785

Robert, C., Kubiszewski, I., Giovannini, E., Lovins, H., McGlade, J., Pickett, K., Vala Ragnarsdóttir, K., Roberts, D., De Vogli, R., Wilkinson, R., 2014. Time to leave GDP behind. Nature 505.

Rockström, J., Steffen, W., Noone, K., Persson, Å., Chapin, F.S., Lambin, E., Lenton, T.M., Scheffer, M., Folke, C., Schellnhuber, H.J., Nykvist, B., de Wit, C.A., Hughes, T., van der Leeuw, S., Rodhe, H., Sörlin, S., Snyder, P.K., Costanza, R., Svedin, U., Falkenmark, M., Karlberg, L., Corell, R.W., Fabry, V.J., Hansen, J., Walker, B., Liverman, D., Richardson, K., Crutzen, P., Foley, J., 2009a. Planetary boundaries: Exploring the safe operating space for humanity. Ecol. Soc. 14.

Rockström, J., Steffen, W., Noone, K., Persson, A., Chapin, F.S., Lambin, E.F., Lenton, T.M., Scheffer, M., Folke, C., Schellnhuber, H.J., Nykvist, B., de Wit, C.A., Hughes, T., van der Leeuw, S., Rodhe, H., Sörlin, S., Snyder, P.K., Costanza, R., Svedin, U., Falkenmark, M., Karlberg, L., Corell, R.W., Fabry, V.J., Hansen, J., Walker, B., Liverman, D., Richardson, K., Crutzen, P., 
Foley, J.A., 2009b. A safe operating space for humanity. Nature 461, 472-5. https://doi.org/10.1038/461472a

Rosa, E.A., Dietz, T., 2012. Human drivers of national greenhouse-gas emissions. Nat. Clim. Chang. $2,581$.

Saez, E., Zucman, G., 2016. Wealth inequality in the United States since 1913: Evidence from capitalized income tax data. Q. J. Econ. 131, 519-578.

Saidi, K., Hammami, S., 2015. The impact of $\mathrm{CO}_{2}$ emissions and economic growth on energy consumption in 58 countries. Energy Reports 1, 62-70.

Schlosberg, D., 2013. Theorising environmental justice: the expanding sphere of a discourse. Env. Polit. 22, 37-55.

Sen, A., 2001. The many faces of gender inequality. New Repub. 35-39.

Shan, Y., Guan, D., Hubacek, K., Zheng, B., Davis, S.J., Jia, L., Liu, J., Liu, Z., Fromer, N., Mi, Z., 2018. City-level climate change mitigation in China. Sci. Adv. 4, eaaq0390.

Smith, P., Davis, S.J., Creutzig, F., Fuss, S., Minx, J., Gabrielle, B., Kato, E., Jackson, R.B., Cowie, A., Kriegler, E., 2016. Biophysical and economic limits to negative $\mathrm{CO}_{2}$ emissions. Nat. Clim. Chang. 6, 42.

Soja, E.W., 2010. Seeking spatial justice. U of Minnesota Press.

Steffen, W., Richardson, K., Rockstrom, J., Cornell, S.E., Fetzer, I., Bennett, E.M., Biggs, R., Carpenter, S.R., de Vries, W., de Wit, C.A., Folke, C., Gerten, D., Heinke, J., Mace, G.M., Persson, L.M., Ramanathan, V., Reyers, B., Sorlin, S., 2015. Planetary boundaries: Guiding human development on a changing planet. Science $80 \quad 347$. https://doi.org/10.1126/science.1259855

Sterner, T., Barbier, E.B., Bateman, I., van den Bijgaart, I., Crépin, A.-S., Edenhofer, O., Fischer, C., Habla, W., Hassler, J., Johansson-Stenman, O., 2019. Policy design for the Anthropocene. Nat. Sustain. 2, 14.

Stevanović, M., Popp, A., Lotze-Campen, H., Dietrich, J.P., Müller, C., Bonsch, M., Schmitz, C., Bodirsky, B.L., Humpenöder, F., Weindl, I., 2016. The impact of high-end climate change on agricultural welfare. Sci. Adv. 2, e1501452.

Sun, J., 1998. Changes in energy consumption and energy intensity: a complete decomposition model. Energy Econ. 20, 85-100.

Tavoni, A., Dannenberg, A., Kallis, G., Löschel, A., 2011. Inequality, communication, and the avoidance of disastrous climate change in a public goods game. Proc. Natl. Acad. Sci. 108, 11825-11829.

Teixidó-Figueras, J., Duro, J.A., 2015. The building blocks of International Ecological Footprint inequality: A Regression-Based Decomposition. Ecol. Econ. 118, 30-39. https://doi.org/10.1016/j.ecolecon.2015.07.014

Teixido-Figueras, J., Steinberger, J.K., Krausmann, F., Haberl, H., Wiedmann, T., Peters, G.P., Duro, J.A., Kastner, T., 2016. International inequality of environmental pressures: Decomposition and comparative analysis. Ecol. Indic. 62, 163-173. https://doi.org/10.1016/j.ecolind.2015.11.041

Teixidó-Figueras, J., Steinberger, J.K., Krausmann, F., Haberl, H., Wiedmann, T., Peters, G.P., Duro, J.A., Kastner, T., 2016. International inequality of environmental pressures: Decomposition and comparative analysis. Ecol. Indic. 62, 163-173. https://doi.org/10.1016/j.ecolind.2015.11.041

Teixido-Figueras, J.J., Duro, J.A., 2012. Ecological Footprint Inequality: A Methodological Review and Some Results. SSRN Electron. J. https://doi.org/10.2139/ssrn.2143081

Teng, F., He, J., Pan, X., Zhang, C., 2011. Metric of Carbon Equity: Carbon Gini Index Based on Historical Cumulative Emission per Capita. Adv. Clim. Chang. Res. 2, 134-140. https://doi.org/10.3724/SP.J.1248.2011.00134

Timmer, M., Erumban, A.A., Gouma, R., Los, B., Temurshoev, U., de Vries, G.J., Arto, I., Genty, V.A.A., Neuwahl, F., Francois, J., 2012. The world input-output database (WIOD): contents, sources and methods. Institue for International and Development Economics.

UNESCO, ISSC and IDS, 2016. World social science report 2016, challenging inequalities: pathways to a just world.

UNFCCC, 2015. Adoption of the Paris Agreement. UNFCCC, Bonn, Germany.

United Nations, 2015. Transforming our world: The 2030 agenda for sustainable development. General Resolution Assembly 70/1, /RES/70/1, 21 October.

United Nations, 2017. United Nations Department of Economic and Social Affairs/Population Division (2017): World Population Prospects: The 2017 Revision.

Van der Veen, M., 2003. When is food a luxury? World Archaeol. 34, 405-427.

Vasconcelos, V. V, Santos, F.C., Pacheco, J.M., Levin, S.A., 2014. Climate policies under wealth 
inequality. Proc. Natl. Acad. Sci. 111, 2212-2216.

Venter, O., Sanderson, E.W., Magrach, A., Allan, J.R., Beher, J., Jones, K.R., Possingham, H.P., Laurance, W.F., Wood, P., Fekete, B.M., 2016. Sixteen years of change in the global terrestrial human footprint and implications for biodiversity conservation. Nat. Commun. 7, 12558.

Walker, G., 2009. Globalizing Environmental Justice The Geography and Politics of Frame Contextualization and Evolution. Glob. Soc. Policy 9, 355-382.

Westing, A.H., 1986. Global resources and international conflict: environmental factors in strategic policy and action. Oxford University Press on Demand.

Wiedmann, T., Lenzen, M., 2018. Environmental and social footprints of international trade. Nat. Geosci. https://doi.org/10.1038/s41561-018-0113-9

Wilk, R., 2002. Consumption, human needs, and global environmental change. Glob. Environ. Chang. $12,5-13$.

Wood, S.A., Smith, M.R., Fanzo, J., Remans, R., DeFries, R.S., 2018. Trade and the equitability of global food nutrient distribution. Nat. Sustain. 1, 34.

The World Bank, 2017. World Development Indicators - DataBank [WWW Document] http://databank.worldbank.org/data/reports.aspx?source=world-development-indicators (accessed 7.6.17). 
Reducing global environmental inequality:

Determining regional quotas for environmental burdens through systems optimisation

C. Pozo, A. Galán-Martín, D. Cortés-Borda, M. Sales-Pardo, A. Azapagic, R. Guimerà, G. GuillénGosálbez

\section{Supplementary material}

The document comprises two main sections. The first, "Supplementary results", presents additional findings omitted in the main manuscript due to space limitations. The second, "Methodology and data", describes: (i) the input-output calculations; (ii) the additive decomposition; (iii) the NLP model reformulation; and (iv) the methodological limitations. It also presents the main data sources used in this study.

\section{Supplementary results}

\subsection{Per-capita consumption of industrial minerals}

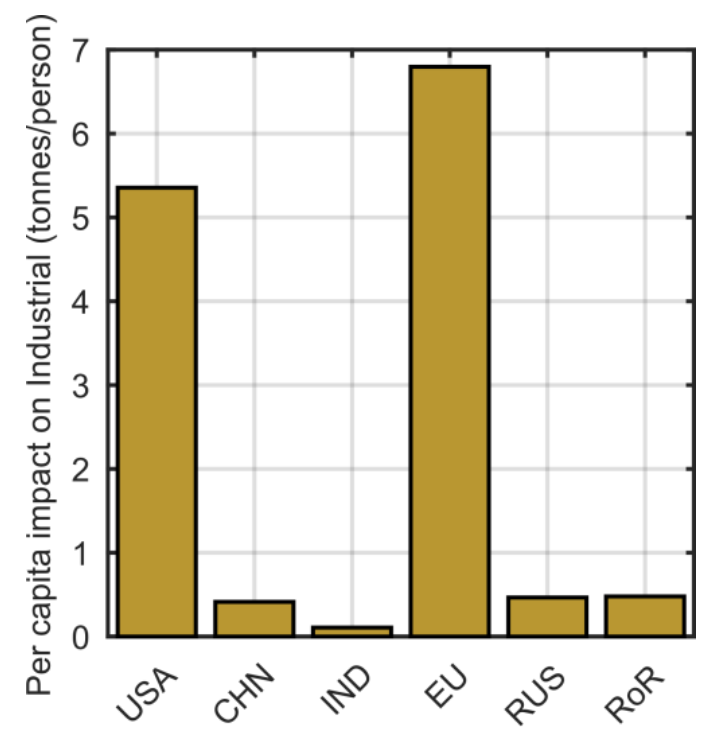

Fig. 1 CB average per-capita burden on industrial minerals for specific regions in the period 1995-2009. EU includes all the WIOD European countries except for Russia and Turkey, while RoR (rest of regions) includes all the remaining WIOD regions not elsewhere classified. 


\subsection{Drivers of environmental global burdens: vertical dimension}

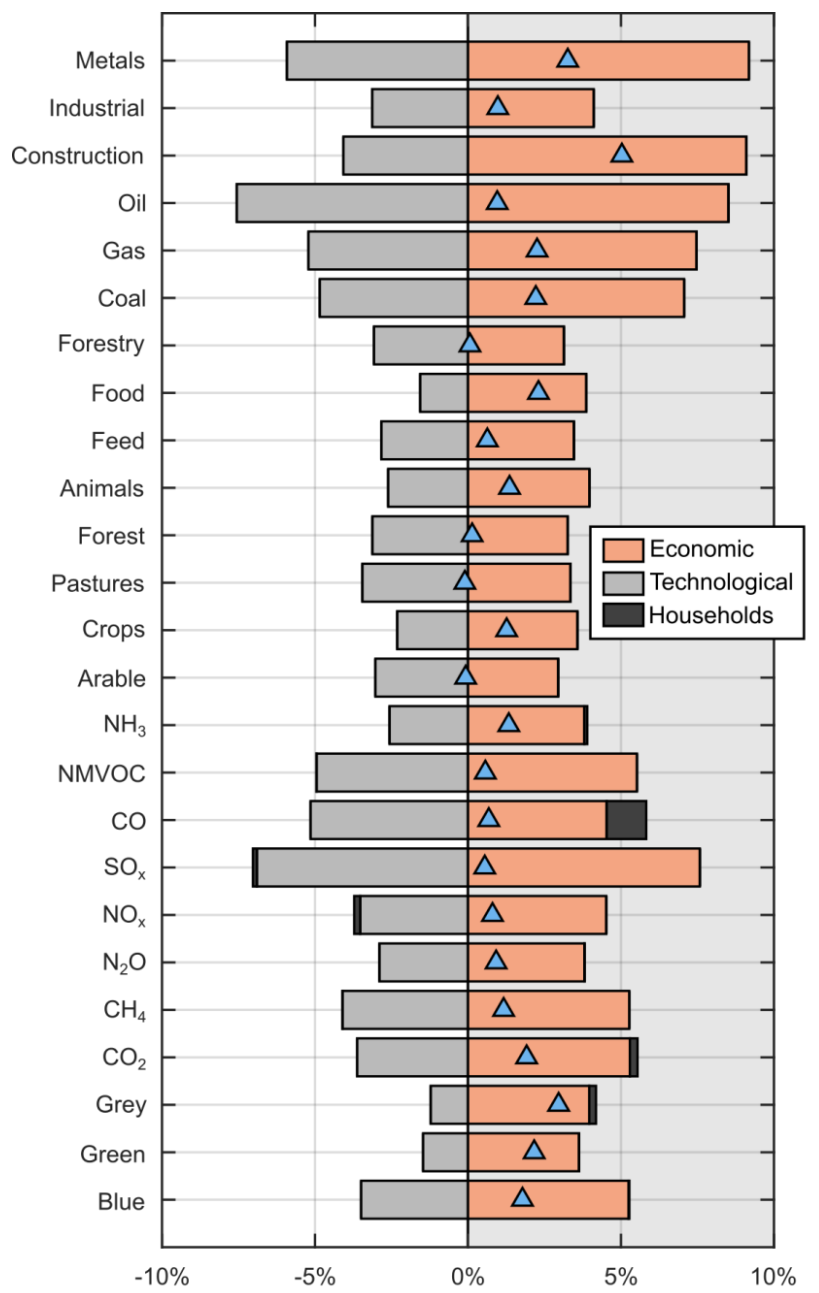

Average contribution to the total burden change per year $(\%)$

Fig. 2 Analysis of the drivers of the changes in total environmental burdens for the period 1995-2009. For each burden, we show the average contribution of each of the three factors towards the annual changes in the total amount of burden generated: economic (salmon), technological (grey) and household factors (black). Blue triangles indicate the average change in global burden within the period. The shaded region on the right-hand side represents contributions towards larger amounts of global burden.

\subsection{Regional quotas for blue water}

In addition to the $\mathrm{CO}_{2}$ case presented in the main manuscript, here we illustrate how our approach could be applied to blue water, as an example of burden currently not transgressing the planetary boundary. To this end, using our barometer, an exemplifying Gini reduction target $\rho$ of $20 \%$ is set (i.e. burden related to the basic needs and with moderate inequality in 2009). This is enforced for 2030 taking 2009 as the reference year. Moreover, we force the maximum disparity to drop by $20 \%$ compared to 2009 levels (i.e. the same reduction as with the Gini), and define a limit of $4,000 \mathrm{~km}^{3} / \mathrm{yr}$ on the total blue water consumed, which is consistent with the estimated capacity of the planet (Kwakkel and Timmermans, 2012; Rockström et al., 2009a).

For the values defined above, the optimal solution entails curbing the per-capita consumption of blue water in Canada (relative decrease of $-19.29 \%$ ) and the USA $(-7.22 \%)$, while allowing for larger consumption in China (relative increase of $+14.18 \%$ ) and RoW $(+4.16 \%)$, and keeping the consumption in the remaining countries unaltered (Supplementary Fig. 3). These targets reflect a situation where the Gini would drop from 0.24 to 0.19 , while decreasing the maximum disparity from $2,335 \mathrm{~m}^{3} /$ cap to $1,868 \mathrm{~m}^{3} / \mathrm{cap}$. The world average per-capita consumption would remain almost the same (from $291 \mathrm{~m}^{3} / \mathrm{cap}$ in 2009, to $290 \mathrm{~m}^{3} / \mathrm{cap}$ in 2030). However, the total blue water consumption would increase by $24.9 \%$ (i.e. from $1,987 \mathrm{~km}^{3} / \mathrm{yr}$ to $2,481 \mathrm{~km}^{3} / \mathrm{yr}$ ) due inter alia to the expected 
population growth $(25.4 \%)$, but still far below the ecological capacity of the planet (estimated at 4,000 $\mathrm{km}^{3} / \mathrm{yr}$ ). Hence, inequality could be reduced via a targeted action focused on a handful of countries.

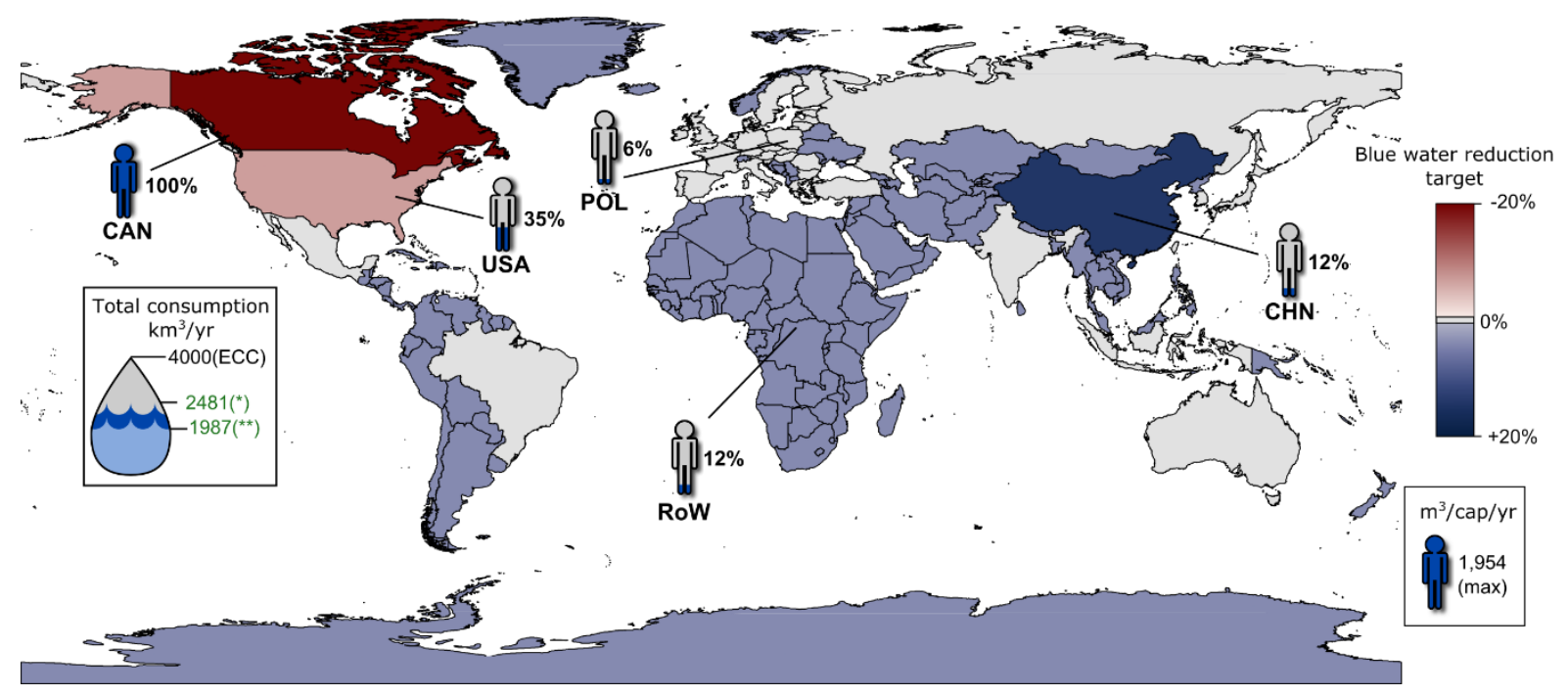

Fig. 3 Region specific targets proposed for 2030 on the per-capita consumption of blue water. Countries are coloured according to the proposed target, expressed as the reduction required in their blue water consumption with respect to their 2009 levels (e.g. Canada would need to reduce its blue water consumption by $19 \%$ compared to its 2009 level). These targets can be translated into the corresponding per-capita blue water consumption allowed in each country, as given within the silhouette of a person and expressed as a percentage of the consumption of the country for which this value is the highest (i.e. Canada, with $1,954 \mathrm{~m}^{3} / \mathrm{cap}$, corresponds to $100 \%)$. The global blue water consumption $\left(\mathrm{km}^{3} / \mathrm{yr}\right)$ is given in the water drop legend, which shows the Earth's carrying capacity (ECC), the current blue water consumption in $2009\left(^{* *}\right)$ and that resulting from the $2030\left(^{*}\right)$ targets.

After agreeing on the national quotas provided by the model, we should decide in a second step on how to meet them in practice. Following the example of blue water, the increase in per-capita consumption allocated to China and RoW might result naturally from their economic growth (i.e. higher GDP would likely increase water consumption) (Steinberger et al., 2012). On the other hand, reductions in blue water could be attained by exploiting key regional abatement opportunities. For example, the high blue water per-capita consumption in Canada is mainly due to hydropower generation (84\% of the CB burden is generated domestically in the sector Electricity, gas and water supply). Hence, to meet its quota, Canada could invest in better technology for hydropower generation while also promoting the move to other renewables. In the case of the USA, 92\% of its total blue water consumption is related to the sectors Agriculture, Hunting, Forestry and Fishing (50\%) and Electricity, gas and water supply (42\%). Thus, the USA could improve water efficiency in agriculture (e.g. drip and sprinkler irrigation) and in industrial/municipal systems, while also optimising the supply-side management (e.g. infrastructure rehabilitation), among other abatement strategies (Addams et al., 2009).

It should be noted that the targets derived from the optimisation approach act as upper bounds of the consumption-based per-capita burdens, which implies that countries which have historically contributed little to the global environmental burdens, in this case to the water consumption, are not forced to increase their burdens just for the sake of reducing the environmental inequality. Due to their economic growth, some developing countries, such as China, are expected to increase their percapita burdens. However, there is evidence that emerging economies can grow without increasing environmental pressures ( $\mathrm{Ma}$ et al., 2019) by taking advantage of technology improvements in developed countries and developing policies that stimulate deployment of low-burden technologies, thus decoupling environmental pressure from economic growth. The upper-bound targets sought are intended to keep the burdens at a level that allows the development of economies without compromising the environmental efficiency or the environmental equality.

When delineating these mitigation options, imported burdens should also be considered as they can play a key role in developed countries, which very often displace burdens to developing countries through imports (Dalin et al., 2017; Davis et al., 2011; Peters et al., 2011). For example, $29 \%$ of the total blue water consumption in the USA is embodied in its imports. In this regard, technology transfers 
from the developed to the developing countries could be encouraged; for example, similar to the Kyoto's Clean Development Mechanism.

Pursuing a more equitable future is not a one-time task, but rather a continuing one: inequality targets should be reviewed periodically, thereby accommodating trends following long-term strategies. Regional quotas could thus be recalculated using updated inputs to deal with potential disturbances, such as conflicts, financial instabilities, technological breakthroughs, etc. By integrating both the vertical (total burden) and horizontal (burden distribution) sustainability dimensions, this tool would, therefore, help to control and monitor the progress made towards sustainable development. This framework would ultimately allow us to move towards a greater sustainability while ensuring safe operation within both dimensions.

\section{Methodology and data}

\subsection{Conceptual framework}

This work combines several analytical tools to study environmental inequality. The insight generated by each of these methods is then combined to develop a systems optimisation framework to tackle inequality more effectively. Data from multi-regional environmentally-extended input-output (MREEIO) tables are employed to analyse the distribution of environmental burdens, investigate the dynamic trends of inequality and identify its main drivers. Environmental inequality is assessed using the Gini coefficient, while additive decomposition is applied to evaluate quantitatively the factors driving inequality changes in the 1995-2009 period. Finally, roadmaps towards higher environmental equality are proposed based on quantitative regional targets determined through systems optimisation.

\subsection{Multi-regional environmentally-extended input-output approach}

Multi-regional input-output (MRIO) models are used to quantify the environmental footprint of each nation for every burden (Hoekstra and Wiedmann, 2014). MRIO tables display the goods and services (expressed in monetary terms) traded between suppliers and consumers along the production chain, across industries/sectors, within a region and between regions (Miller and Blair, 2009). The environmental extension of the MRIO tables (i.e. MREEIO) provides information on the environmental burdens generated by the economic activities carried out within sectors, which are embodied in the goods and services traded between them. Here we follow a consumption-based (CB) accounting system, which quantifies the burdens embodied in the goods/services consumed by a country, regardless of where the burdens are generated along the products' supply chains.

In the CB system, we quantify environmental burdens at the demand side, that is, the burdens generated globally to satisfy the demand of a country (i.e. environmental footprint). This is done in two steps. First, Supplementary Eq. (1) is applied to calculate the economic output $X^{C B r}$ required in all the economic activities across the world to satisfy the demand $Y R^{r}$ of a region $r$. To this end, we use the so-called Leontief inverse matrix $(I-A)^{-1}$, as follows:

$$
X^{C B r}=(I-A)^{-1} Y R^{r} \forall r
$$

In matrix form, the terms in Supplementary Eq. (1) can be expressed as follows:

$$
X^{C B r}=\left(\begin{array}{c}
x_{11}^{C B r} \\
x_{i r \prime}^{C B r} \\
\vdots \\
x_{n p}^{C B r}
\end{array}\right) ; I=\left(\begin{array}{cccc}
1 & 0 & 0 & 0 \\
0 & 1 & \cdots & 0 \\
\vdots & \vdots & \ddots & \vdots \\
0 & 0 & \cdots & 1
\end{array}\right) ; A=\left(\begin{array}{cccc}
a_{11}^{11} & a_{1 j}^{1 r \prime} & \cdots & a_{1 n}^{1 p} \\
a_{i 1}^{r 1} & a_{i j}^{r r \prime} & \cdots & a_{i n}^{r p} \\
\vdots & \vdots & \ddots & \vdots \\
a_{n 1}^{p 1} & a_{n j}^{p r \prime} & \cdots & a_{n n}^{p p}
\end{array}\right) ; Y R^{r}=\left(\begin{array}{c}
y r_{11}^{r} \\
y r_{i r \prime}^{r} \\
\vdots \\
y r_{n p}^{r}
\end{array}\right)
$$

where $X^{C B r}$ is the economic output CB required in all the economic activities to satisfy the demand of region $r$ (i.e. vector of $n \cdot p$ elements $x_{i r r}^{C B r}$, each associated with an economic activity $i$ of a region $r$, where $n$ is the total number of activities and $p$ is the total number of regions). I is the identity matrix and $A$ contains $(n \cdot p) x(n \cdot p)$ technical coefficient elements $\left\{a_{i j}^{r r \prime}\right\}$, which are calculated as $a_{i j}^{r r \prime}=$ $z_{i j}^{r r \prime} / x_{j}^{r \prime}$. Here, $z_{i j}^{r r \prime}$ corresponds to inter-activity economic flows from economic activity $i$ in region $r$ to economic activity $j$ in region $r$, and $x_{j}^{r \prime}$ represents the total output of each economic activity $j$ within 
each region $r$ '. Finally, $Y R^{r}$ is the vector containing the goods and services demanded by each region $r$ to each of the $n$ economic activities in the $p$ regions $r$ '.

In the second step, the economic flows $X^{C B r}$ calculated in step one are translated into the corresponding burdens. This is done using burden intensities defined for each economic activity (parameter $B I_{b}$ ), as shown in Supplementary Eq. (3):

$$
W_{b}^{C B r}=X^{C B r} \circ B I_{b}{ }^{T}=\left[\begin{array}{c}
w_{11 b}^{C B r} \\
w_{i r \prime b}^{C B r} \\
\vdots \\
w_{n p b}^{C B r}
\end{array}\right] \forall r, b
$$

where "o" is the Hadamard product, $W_{b}^{C B r}$ is a vector containing $n \cdot p$ elements $w_{i r \prime b}^{C B r}$, each denoting the amount of burden $b$ generated by economic activity $i$ in region $r$ ' to satisfy the demand from end users in region $r$, while $B I_{b}$ is the vector of environmental burden intensities for burden $b$ (burden generated per unit of economic output, which depends on the economic activity). This vector contains $n \cdot p$ elements, where each of them corresponds to the burden intensity of a given activity in a specific country. Hence, the $\mathrm{CB}$ environmental burden of region $r$ for indicator $b$, denoted by $w r_{r b}^{C B}$, is obtained by aggregating the burdens $b$ generated in all the economic activities across the world to satisfy the demand from region $r$ (i.e. $w_{i r l b}^{C B r}$ ), plus the domestic burdens from households in the consumer region $\left(H H_{r b}\right)$, as illustrated by Supplementary Eq. (4).

$$
w r_{r b}^{C B}=\sum_{r \prime} \sum_{i} w_{i r \prime b}^{C B r}+H H_{r b} \quad \forall r, b
$$

\subsection{Additive decomposition: Gini coefficient and global burden}

\subsubsection{Interactions allocation}

In our work, changes in Ginis are decomposed into the ceteris paribus contributions of four factors plus their interactions following the additive decomposition proposed by Biewen (2014, 2012). These interactions reflect the effect that appears when more than one factor is modified at the same time causing the overall change to be different from the additive contribution of modifying each of the factors in isolation (i.e. ceteris paribus changes). The interactions can be classified according to the number of factors considered in each case. For instance, two-way interactions result from the simultaneous change of two factors. Therefore, the number of interactions of a $k$-way interaction equals the number of combinations of $k$ factors among the total set of $f$ factors. In our case, we examine four factors (demographic, economic, technological and household), so there are $\left(\begin{array}{l}4 \\ 2\end{array}\right)=6$ two-way interactions, which are calculated using Supplementary Eqs. (5)-(10):

$$
\begin{aligned}
& \operatorname{Int} 2_{b}^{1100}=\left(\operatorname{Gini}_{b}^{1100}-\operatorname{Gini}_{b}^{0000}\right)-\left(\operatorname{Gini}_{b}^{1000}-\operatorname{Gini}_{b}^{0000}\right)-\left(\operatorname{Gini}_{b}^{0100}-\operatorname{Gini}_{b}^{0000}\right) \quad \forall b \\
& \text { Int } 2_{b}^{1010}=\left(\text { Gini }_{b}^{1010}-\text { Gini }_{b}^{0000}\right)-\left(\text { Gini }_{b}^{1000}-\text { Gini }_{b}^{0000}\right)-\left(\text { Gini }_{b}^{0010}-\text { Gini }_{b}^{0000}\right) \quad \forall b \\
& \operatorname{Int} 2_{b}^{1001}=\left(\operatorname{Gini}_{b}^{1001}-\operatorname{Gini}_{b}^{0000}\right)-\left(\operatorname{Gini}_{b}^{1000}-\operatorname{Gini}_{b}^{0000}\right)-\left(\operatorname{Gini}_{b}^{0001}-\operatorname{Gini}_{b}^{0000}\right) \quad \forall b \\
& \operatorname{Int} 2_{b}^{0110}=\left(\operatorname{Gini}_{b}^{0110}-\operatorname{Gini}_{b}^{0000}\right)-\left(\operatorname{Gini}_{b}^{0100}-\operatorname{Gini}_{b}^{0000}\right)-\left(\operatorname{Gini}_{b}^{0010}-\operatorname{Gini}_{b}^{0000}\right) \quad \forall b \\
& \operatorname{Int} 2_{b}^{0101}=\left(\operatorname{Gini}_{b}^{0101}-\operatorname{Gini}_{b}^{0000}\right)-\left(\operatorname{Gini}_{b}^{0100}-\operatorname{Gini}_{b}^{0000}\right)-\left(\operatorname{Gini}_{b}^{0001}-\operatorname{Gini}_{b}^{0000}\right) \quad \forall b \\
& \operatorname{Int} 2_{b}^{0011}=\left(\text { Gini }_{b}^{0011}-\operatorname{Gini}_{b}^{0000}\right)-\left(\operatorname{Gini}_{b}^{0010}-\operatorname{Gini}_{b}^{0000}\right)-\left(\operatorname{Gini}_{b}^{0001}-\operatorname{Gini}_{b}^{0000}\right) \quad \forall b
\end{aligned}
$$

Here, $\operatorname{Int} 2_{b}^{\text {deth }}$ is the interaction associated to the simultaneous modification of two factors. The superscripts denote each of the four factors appearing in the following order: $d$ for demographic, $e$ for economic, $t$ for technological and $h$ for household. A value of 1 in the subscript indicates that the factor is set to its value in the second time period (i.e. it is modified), while a value of 0 denotes that it is fixed to its value in the first time period (i.e. it remains the same). For instance, $\operatorname{Int} 2_{b}^{1100}$ corresponds to the interactions taking place when modifying factors one (demographics) and two (economics), that is, when fixing them to their values in time period two, while keeping factors three and four at their periodone values. Two-way interactions are calculated by subtracting the ceteris paribus effect of the two factors (second and third terms between parenthesis in the right-hand side of the equations) from the 
overall change incurred when these two factors are modified simultaneously (first summand on the right-hand side).

Similarly, the four three-way interactions are calculated as follows:

$$
\begin{aligned}
& \operatorname{Int} 3_{b}^{1110}=\left[\operatorname{Gini}_{b}^{1110}-\operatorname{Gini}_{b}^{0000}\right]-\left[\operatorname{Int} 2_{b}^{1100}+\operatorname{Int} 2_{b}^{1010}+\operatorname{Int} 2_{b}^{0110}\right]- \\
& -\left[\left(\operatorname{Gini}_{b}^{1000}-\operatorname{Gini}_{b}^{0000}\right)+\left(\operatorname{Gini}_{b}^{0100}-\operatorname{Gini}_{b}^{0000}\right)+\left(\operatorname{Gini}_{b}^{0010}-\operatorname{Gini}_{b}^{0000}\right)\right] \quad \forall b \\
& \operatorname{Int} 3_{b}^{1101}=\left[\operatorname{Gini}_{b}^{1101}-\operatorname{Gini}_{b}^{0000}\right]-\left[\operatorname{Int} 2_{b}^{1100}+\operatorname{Int} 2_{b}^{1001}+\operatorname{Int} 2_{b}^{0101}\right]- \\
& -\left[\left(\operatorname{Gini}_{b}^{1000}-\operatorname{Gini}_{b}^{0000}\right)+\left(\operatorname{Gini}_{b}^{0100}-\operatorname{Gini}_{b}^{0000}\right)+\left(\operatorname{Gini}_{b}^{0001}-\operatorname{Gini}_{b}^{0000}\right)\right] \quad \forall b \\
& \operatorname{Int} 3_{b}^{1011}=\left[\operatorname{Gini}_{b}^{1011}-\operatorname{Gini}_{b}^{0000}\right]-\left[\operatorname{Int} 2_{b}^{1010}+\operatorname{Int} 2_{b}^{1001}+\operatorname{Int} 2_{b}^{0011}\right]- \\
& -\left[\left(\operatorname{Gini}_{b}^{1000}-\operatorname{Gini}_{b}^{0000}\right)+\left(\operatorname{Gini}_{b}^{0010}-\operatorname{Gini}_{b}^{0000}\right)+\left(\operatorname{Gini}_{b}^{0001}-\operatorname{Gini}_{b}^{0000}\right)\right] \quad \forall b \\
& \operatorname{Int} 3_{b}^{0111}=\left[\operatorname{Gini}_{b}^{0111}-\operatorname{Gini}_{b}^{0000}\right]-\left[\operatorname{Int} 2_{b}^{0110}+\operatorname{Int} 2_{b}^{0101}+\operatorname{Int} 2_{b}^{0011}\right]- \\
& -\left[\left(\operatorname{Gini}_{b}^{0100}-\operatorname{Gini}_{b}^{0000}\right)+\left(\operatorname{Gini}_{b}^{0010}-\operatorname{Gini}_{b}^{0000}\right)+\left(\operatorname{Gini}_{b}^{0001}-\operatorname{Gini}_{b}^{0000}\right)\right] \quad \forall b
\end{aligned}
$$

The terms between brackets on the right-hand side of Supplementary Eqs. (11) -(14) are as follows: the first one is the overall change occurring when the three factors are modified simultaneously; the second one discounts the three two-way interactions between these three factors; and finally the third term subtracts their ceteris paribus contributions.

The four-way interactions are given by the mismatch between the overall change and the additive contribution of the ceteris paribus effects plus the two- and three-way interactions:

$$
\begin{gathered}
\text { Int } 4_{b}^{1111}=\left[\operatorname{Gini}_{b}^{1111}-\operatorname{Gini}_{b}^{0000}\right]-\left[\operatorname{Int} 3_{b}^{1110}+\operatorname{Int} 3_{b}^{1101}+\operatorname{Int} 3_{b}^{1011}+\operatorname{Int} 3_{b}^{0111}\right] \\
-\left[\operatorname{Int} 2_{b}^{1100}+\operatorname{Int} 2_{b}^{1010}+\operatorname{Int} 2_{b}^{1001}+\operatorname{Int} 2_{b}^{0110}+\operatorname{Int} 2_{b}^{0101}+\operatorname{Int} 2_{b}^{0011}\right] \\
-\left[\left(\operatorname{Gini}_{b}^{1000}-\operatorname{Gini}_{b}^{0000}\right)+\left(\operatorname{Gini}_{b}^{0100}-\operatorname{Gini}_{b}^{0000}\right)\right. \\
\left.+\left(\operatorname{Gini}_{b}^{0010}-\operatorname{Gini}_{b}^{0000}\right)+\left(\operatorname{Gini}_{b}^{0001}-\operatorname{Gini}_{b}^{0000}\right)\right] \forall b
\end{gathered}
$$

We finally allocate each of the interactions among the different factors involved in them following the "jointly contributed and equally divided" principle (Sun, 1998), whereby all the interactions of a given $k$ way are allocated $1 / k^{\text {th }}$ to each of the corresponding factors. Therefore, according to this principle, one half of each of the two-way interactions is allocated to each of its contributing factors, while three-way interactions are split and allocated in thirds, and the four-way interaction is distributed in quarters (Supplementary Eqs. (16)-(19)):

$$
\begin{array}{r}
F C_{b}^{1000}=\left[\operatorname{Gini}_{b}^{1000}-\operatorname{Gini}_{b}^{0000}\right]+\frac{1}{2}\left[\operatorname{Int} 2_{b}^{1100}+\operatorname{Int} 2_{b}^{1010}+\operatorname{Int} 2_{b}^{1001}\right] \\
+\frac{1}{3}\left[\operatorname{Int} 3_{b}^{1110}+\operatorname{Int} 3_{b}^{1101}+\operatorname{Int} 3_{b}^{1011}\right]+\frac{1}{4}\left[\operatorname{Int} 4_{b}^{1111}\right] \forall b \\
F C_{b}^{0100}=\left[\operatorname{Gini}_{b}^{0100}-\operatorname{Gini}_{b}^{0000}\right]+\frac{1}{2}\left[\operatorname{Int} 2_{b}^{1100}+\operatorname{Int} 2_{b}^{0110}+\operatorname{Int} 2_{b}^{0101}\right] \\
+\frac{1}{3}\left[\operatorname{Int} 3_{b}^{1110}+\operatorname{Int} 3_{b}^{1101}+\operatorname{Int} 3_{b}^{0111}\right]+\frac{1}{4}\left[\operatorname{Int} 4_{b}^{1111}\right] \forall b \\
F C_{b}^{0010}=\left[\operatorname{Gini}_{b}^{0010}-\operatorname{Gini}_{b}^{0000}\right]+\frac{1}{2}\left[\operatorname{Int} 2_{b}^{1010}+\operatorname{Int} 2_{b}^{0110}+\operatorname{Int} 2_{b}^{0011}\right] \\
+\frac{1}{3}\left[\operatorname{Int} 3_{b}^{1110}+\operatorname{Int} 3_{b}^{1011}+\operatorname{Int} 3_{b}^{0111}\right]+\frac{1}{4}\left[\operatorname{Int} 4_{b}^{1111}\right] \forall b \\
F C_{b}^{0001}=\left[\operatorname{Gini}_{b}^{0001}-\operatorname{Gini}_{b}^{0000}\right]+\frac{1}{2}\left[\operatorname{Int} 2_{b}^{1001}+\operatorname{Int} 2_{b}^{0101}+\operatorname{Int} 2_{b}^{0011}\right] \\
+
\end{array}
$$

where $F C_{b}^{\text {deth }}$ is the final contribution of the factor denoted by the superscript following the same notation as before: 1000 for demographic, 0100 for economic, 0010 for technological and 0001 for household factors. This methodology allows decomposing the total Gini change into the individual factors in an exact and unambiguous manner, so that Supplementary Eq. (20) holds:

$$
\operatorname{Gini}_{b}^{1111}-G i n i_{b}^{0000}=F C_{b}^{1000}+F C_{b}^{0100}+F C_{b}^{0010}+F C_{b}^{0001} \forall b
$$


Note that before calculating all the terms in the decomposition, it is necessary to express all the monetary flows in the same currency in a given reference year. In our case, all the flows are expressed in 1995 US\$ using the appropriate deflators sourced from the World Bank (n.d.).

\subsection{Vertical dimension: decomposition of the total burden}

In the main manuscript, we explored the contribution of four factors - demographic, economic, technological and household - to the total Gini variations (horizontal dimension of sustainability). To complement this analysis, we here investigate the drivers behind the changes in the total burdens generated worldwide (vertical dimension of sustainability). To this end, we decompose Eq. (2) in the main manuscript (i.e. $w r_{r b}^{C B}=B I_{b} X^{C B r}+H H_{r b}$ ) into the economic $\left(X^{C B r}\right)$, technological $\left(B I_{b}\right)$ and household $\left(H_{r b}\right)$ factors, plus their interactions following Supplementary Eqs. (21)-(24).

$$
\begin{aligned}
& \sum_{r}^{p} w r_{r b}^{C B 111}-\sum_{r}^{p} w r_{r b}^{C B 000}=\left(\sum_{r}^{p} w r_{r b}^{C B 100}-\sum_{r}^{p} w r_{r b}^{C B 000}\right) \\
& +\left(\sum_{\substack{r \\
p}}^{p} w r_{r b}^{C B 010}-\sum_{\substack{p \\
p}}^{p} w r_{r b}^{C B 000}\right) \\
& +\left(\begin{array}{c}
\sum_{r}^{p} w r_{r b}^{C B 001}-\sum_{r}^{p} w r_{r b}^{C B 000} \\
+ \text { Interactions } W_{b} \quad \forall b
\end{array}\right)
\end{aligned}
$$

Here, $w r_{r b}^{C B e t h}$ denotes the CB burden $b$ of region $r$ where each of the superscripts refers to one factor: $e$ for economic, $t$ for technological and $h$ for household.

Note that population is omitted as it grew in all the countries during 1995-2009. Hence, it contributed to increase the burdens in all of the categories, as more population leads to more consumption (assuming the same per-capita consumption rate). There is, therefore, no need to consider the demographic factor in the decomposition of the total burdens. The value of the superscript denotes the year for which the corresponding factor is evaluated: 0 for the first year and 1 for the second one. Therefore, Supplementary Eqs. (21)-(24) compute the ceteris paribus contributions of each of the three factors towards the change in the global burden, whereas the Interactions $W_{b}$ term is allocated following a procedure analogous to the one presented in the previous section for estimating the interactions of the CB Ginis (Sun, 1998). Hence, we apply here the following equations:

$$
\begin{aligned}
F C W_{b}^{100} & =\left[\sum_{r}^{p} w r_{r b}^{C B 100}-\sum_{r}^{p} w r_{r b}^{C B 000}\right]+\frac{1}{2}\left[\operatorname{Int} 2 W_{b}^{110}+\operatorname{Int} 2 W_{b}^{101}\right]+\frac{1}{3}\left[\operatorname{Int} 3 W_{b}^{111}\right] \forall b \\
F C W_{b}^{010} & =\left[\sum_{r}^{p} w r_{r b}^{C B 010}-\sum_{r}^{p} w r_{r b}^{C B 000}\right]+\frac{1}{2}\left[\operatorname{Int} 2 W_{b}^{110}+\operatorname{Int} 2 W_{b}^{011}\right]+\frac{1}{3}\left[\operatorname{Int} 3 W_{b}^{111}\right] \forall b \\
F C W_{b}^{d 001} & =\left[\sum_{r}^{p} w r_{r b}^{C B 001}-\sum_{r}^{p} w r_{r b}^{C B 000}\right]+\frac{1}{2}\left[\operatorname{Int} 2 W_{b}^{101}+\operatorname{Int} 2 W_{b}^{011}\right]+\frac{1}{3}\left[\operatorname{Int} 3 W_{b}^{111}\right] \forall b
\end{aligned}
$$

where $F C W_{b}^{\text {eth }}$ denotes the total contribution of the factor specified by the corresponding superscript in the term towards the change in global burden $b$ : 100 for economic, 010 for technological and 001 for household factors. The values reported in our work for each indicator correspond to the average of the contributions across all the different pairs of years during the period 1995-2009, where monetary values are expressed in 1995 US\$.

\subsection{Optimisation model: linear reformulation}

In this contribution, we propose a mathematical programming model that determines optimal regional quotas on the per-capita generation of burdens that deviate the least from current levels. While doing so, the model ensures that the solution sought satisfies in turn a set of constraints: (i) a specific maximum allowable level of inequality (imposed via an upper bound on the Gini coefficient); (ii) a 
maximum limit on the disparities in per-capita burdens between regions; and (iii) a limit on the total burden generated globally.

The model proposed in this work (see Materials and Methods in main manuscript) takes the form of a nonlinear programming problem (NLP). To facilitate its solution, the original model is reformulated into an equivalent linear programming (LP) formulation following standard mathematical techniques. To this end, we replace the absolute value function by a positive variable whose value is enforced using two linear expressions, each covering one possible sign of the argument of the function (i.e. positive and negative). Hence, the original absolute value in the objective function (Eq. (13)) is replaced by Supplementary Eqs. (36) and (37), while the absolute value in the Gini assessment (Eq. (14)) is replaced by Supplementary Eqs. (33) and (34). The resulting linear programming (LP) model proposed herein is expressed as follows (Supplementary Eqs. (29)-(38)):

$$
\begin{aligned}
& \min \sum_{r} \frac{A V C H_{r}}{\mathrm{PC}_{\mathrm{r}}^{\mathrm{REF}}} \\
& \text { s.t. } \frac{\sum_{r} \sum_{r \prime} \text { pop }_{\mathrm{r}} \text { pop }_{\mathrm{r},}{ }{ }_{1 S P_{r, r \prime}}}{2 \sum_{r} \operatorname{pop}_{\mathrm{r}} \sum_{r} P C_{r}} \leq \overline{\text { Gini }} \\
& \sum_{r}\left(P C_{r} \text { pop }_{\mathrm{r}}\right) \leq \overline{\mathrm{TB}} \\
& D_{I S P_{r, r}} \leq \overline{\mathrm{DISP}} \quad \forall r, r^{\prime} \\
& D I S P_{r, r} \geq P C_{r}-P C_{r^{\prime}} \quad \forall r, r^{\prime} \\
& D I S P_{r, r} \geq P C_{r^{\prime}}-P C_{r} \quad \forall r, r^{\prime} \\
& D I S P_{r, r}=D I S P_{r, r} \quad \forall r, r^{\prime} \\
& A V C H_{r} \geq P C_{r}-\mathrm{PC}_{\mathrm{r}}^{\mathrm{REF}} \forall r \\
& A V C H_{r} \geq \mathrm{PC}_{\mathrm{r}}^{\mathrm{REF}}-P C_{r} \quad \forall r \\
& A V C H_{r}, D I S P_{r, r}, P C_{r} \in \mathbb{R}_{\geq 0} \quad \forall r, r^{\prime}
\end{aligned}
$$

In this LP, the objective function (Supplementary Eq. (29)) seeks to minimise the relative total change between the current $\mathrm{CB}$ per-capita burden $\left(\mathrm{PC}_{\mathrm{r}}^{\mathrm{REF}}\right)$ and the optimal $\mathrm{CB}$ targets (i.e. regional quotas on burdens) for all regions $r\left(P C_{r}\right)$. The difference between the current value of the burden and the optimal value determined by the model is represented by variable $A V C H_{r}$. This variable is forced to be always positive (i.e. it is defined as a positive variable) while at the same time lying above the positive and negative differences between the two burden values mentioned above, as shown in Supplementary Eqs. (36) and (37). Note that here we assume the same weight to the changes upwards (e.g. $+5 \%$ ) and downwards (e.g. $-5 \%$ ). Supplementary Eqs. (30) and (31) impose an upper bound on the inequality level (parameter $\overline{\text { Gini) }}$ ) as well as on the total burden generated (parameter $\overline{\mathrm{TB}}$ ), respectively (horizontal and vertical dimensions of sustainability). Then, Supplementary Eq. (32) forces the maximum disparities in per-capita burdens between regions (variable $D I S P_{r, r}$ ) to lie below a desired level (parameter $\overline{\mathrm{DISP}}$ ). Variable $D I S P_{r, r}$, refers to the absolute value of the disparity in percapita burdens between regions $r$ (variable $P C_{r}$ ) and $r^{\prime}\left(P C_{r_{1}}\right)$, as calculated in Supplementary Eqs. (33) and (34). Supplementary Eq. (35) exploits symmetry properties to expedite calculations. The model could also incorporate other equations, such as burden-specific constraints describing the regional vulnerability to local impacts (see Methodological limitations).

Note that all variables (depicted in italics in this model) and parameters (in regular font) apply for the target year, except for those with superscript REF, which are defined for the reference year. In these equations, the population of each region $r$ is a given parameter $\left(\operatorname{pop}_{\mathrm{r}}\right)$ whose value was retrieved from the UN populations prospects assuming a medium variant scenario (United Nations, 2017). The nomenclature used in the model is provided in Supplementary Table 1.

The LP was implemented in the General Algebraic Modelling System (GAMS) version 24.4.1 (Brooke et al., 1998). The model features 1,765 continuous variables and 5,088 constraints, and was solved with CPLEX 24.4.6 on an AMD A8-5500 APU with Raedon 3.20 Ghz and 8.0 GB RAM. The solution time was below $1 \mathrm{CPU}$ second in the aforementioned computer. 
Table 1 Nomenclature for the LP model.

\begin{tabular}{ll}
\hline Index & Index for regions \\
$r$ & Per-capita consumption-based burden of region $r$ in the reference year REF \\
\hline \begin{tabular}{ll} 
Parameters \\
$\mathrm{PC}_{\mathrm{r}}^{\mathrm{REF}}$ & Estimate for the population of each region $r$ \\
pop $_{\mathrm{r}}$ & Upper bound on inequality level established on Gini \\
$\overline{\mathrm{Gini}}$ & Upper bound on the global total burden \\
$\overline{\mathrm{TB}}$ & Upper bound on disparities between regions \\
$\overline{\mathrm{DISP}}$ & Change in per-capita consumption-based burden of region $r$ between the reference year and the \\
\hline Continuous variables & \\
$A V C H_{r}$ & optimal quota \\
$D I S P_{r, r}$, & Disparity in per-capita consumption-based burden between region $r$ and $r$
\end{tabular} \\
$P C_{r}$ & Quota imposed on the per-capita consumption-based burden of region $r$ \\
\hline
\end{tabular}

\subsection{Data sources}

The amounts of burdens generated by each economic activity were obtained from MREEIO tables (Cortés-Borda et al., 2015; Leontief, 1936; Miller and Blair, 2009; Pascual-González et al., 2015; Wiedmann, 2009a). In particular, we used the World Input Output Database (WIOD) (Dietzenbacher et al., 2013; Timmer et al., 2012), which covers 35 economic activities for 41 regions (40 countries and a region labelled as "Rest of the World" (RoW) that aggregates the remaining countries; Supplementary Table 2). The 35 economic activities are classified here into the three economic sectors (primary, secondary and tertiary) according to the NACE Rev. 2 codes (European Commission, 2017) provided by the database, as follows:

- Economic activity $c 1$ (Agriculture, Hunting, Forestry and Fishing) is the only one contributing to the primary sector.

- Economic activities $c 2$ to $c 18$ (from Mining and Quarrying to Construction) are attributed to the secondary sector.

- Contributions to the tertiary sector correspond to economic activities c19 to c35 (from Sale, Maintenance and Repair of Motor Vehicles and Motorcycles; Retail Sale of Fuel, to Private Households with Employed Persons.

In WIOD, the contribution of Households towards the global economy is provided separately from the 35 economic activities.

Table 2 Countries and regions considered in the study.

\begin{tabular}{llllll}
\hline Countries and regions & & & & \\
\hline Australia & Cyprus & Greece & Latvia & Portugal & Sweden \\
Austria & Czech Republic & Hungary & Lithuania & Romania & Taiwan \\
Belgium & Denmark & India & Luxemburg & Russia & Turkey \\
Bulgaria & Estonia & Indonesia & Malta & Slovak Republic & United Kingdom \\
Brazil & Finland & Ireland & Mexico & Slovenia & USA \\
Canada & France & Italy & Netherlands & South Korea & Rest of the World \\
China & Germany & Japan & Poland & Spain & \\
\hline
\end{tabular}

The database also includes 70 environmental burdens for the period 1995-2009; for further details, see the original references (Dietzenbacher et al., 2013; Timmer et al., 2015). We focus on 25 out of the 70 environmental burdens available (see Supplementary Table 3), after omitting energy indicators and burdens labelled as "others" (i.e. "biomass other" and "fossil other") and summing up the "used" and "unused" burdens as described in the main manuscript. The 25 environmental burdens considered in the analysis are split across four environmental categories: materials, water, land and emissions. 
Table 3 Categories and burdens considered in the study.

\begin{tabular}{|c|c|c|c|c|c|}
\hline $\begin{array}{l}\text { Materials } \\
\text { Biomass }\end{array}$ & Fossil & Minerals & Water & Land & Emissions \\
\hline $\begin{array}{l}\text { Animals } \\
\text { Feed } \\
\text { Food } \\
\text { Forestry }\end{array}$ & $\begin{array}{l}\text { Coal } \\
\text { Gas } \\
\text { Oil }\end{array}$ & $\begin{array}{l}\text { Construction } \\
\text { Industrial } \\
\text { Metals }\end{array}$ & $\begin{array}{l}\text { Blue } \\
\text { Green } \\
\text { Grey }\end{array}$ & $\begin{array}{l}\text { Arable } \\
\text { Permanent crops } \\
\text { Pastures } \\
\text { Forest }\end{array}$ & $\begin{array}{l}\mathrm{CO}_{2} \\
\mathrm{CH}_{4} \\
\mathrm{~N}_{2} \mathrm{O} \\
\mathrm{NO}_{x} \\
\mathrm{SO}_{x} \\
\mathrm{CO} \\
\mathrm{NMVOC} \mathrm{NH}_{3}\end{array}$ \\
\hline
\end{tabular}

The materials category is split into three subcategories: biomass-based materials, fossil materials and minerals. The indicators within the biomass subcategory are animals (fish and meat), food (cereals, vegetables or fruits for human consumption), feed (fodder for cattle) and forestry (e.g. wood). The fossil subcategory comprises three indicators: coal, gas and oil. Finally, three types of mineral are in the third subcategory: construction (e.g. clays or sand and gravel for concrete), industrial (e.g. calcite, graphite or sulphur) and metals.

The water category includes blue, green and grey water, which represent, respectively, the amount of ground and surface water, rainwater and polluted water required to produce goods and services. Green water is mostly consumed in the agricultural sector, whereas blue water shows significant contributions from both the primary sector (i.e. irrigation) and the secondary sector (e.g. hydroelectricity; see sectoral contribution in Fig. 2 in the main manuscript. Grey water receives contributions from the primary and secondary sectors as well as from households (e.g. baths, sinks or washing machines).

In the land-use category, the area dedicated to crops is classified as either arable - accounting for land devoted to temporary crops - and permanent - referring to the land cultivated for long periods and not requiring replanting after each harvest (Economic, 2001). The area containing herbaceous forage crops used for animals grazing is allocated to the indicator pastures area. The forest indicator provides the forest area being used for productive purposes - mostly related to the formation of wood biomass.

Finally, the emissions category comprises $\mathrm{CO}_{2}, \mathrm{CH}_{4}, \mathrm{~N}_{2} \mathrm{O}, \mathrm{NO} \mathrm{O}_{x}, \mathrm{SO}_{x}, \mathrm{CO}, \mathrm{NMVOC}$, and $\mathrm{NH}_{3}$ emissions, which are connected mainly to industrial activities and services. Within this group, $\mathrm{CH}_{4}$, $\mathrm{N}_{2} \mathrm{O}$, and $\mathrm{NH}_{3}$ emissions are mostly generated in the agricultural sector (e.g. fertilisers), with $\mathrm{CH}_{4}$ showing also a significant contribution from the secondary sector (i.e. mining). In addition, households show a large contribution towards $\mathrm{CO}_{2}, \mathrm{NO}_{x}, \mathrm{CO}$ and $\mathrm{NMVOC}$ emissions, since a significant share of these emissions comes from conventional gasoline/diesel vehicles.

\subsection{Methodological limitations}

The analytical tools employed in our work show some limitations as discussed below, which we believe do not affect the main insights of our analysis:

- Input-output analysis relies on linear models that assume that the economic output is linearly proportional to the demand regardless of the scale of the economy. This implies that the economies of scale play no role in the generation of environmental burdens. This assumption might be more critical in standard 10 studies where the demand is modified to predict how the economy will cope with such change (Miller and Blair, 2009). While in our case the demand is always constant, we calculate CB per-capita burdens by taking the demand of one country at a time and assuming that the amount of burdens generated per unit of money traded is the same regardless of the demand size. In practice, low demands might lead to larger amounts of burdens per unit of money traded compared to higher demands. This linear assumption is, nevertheless, widely used and accepted in the scientific community (Davis et al., 2011; Miller and Blair, 2009; Peters, 2008; Steen-Olsen et al., 2014; Wiedenhofer et al., 2017; Wiedmann, 2009b; Wiedmann et al., 2011). 
- Another limitation of the 10 tables concerns the level of aggregation of economic activities (Wiedmann, 2009b). These tables assume that all the subsectors within a given economic activity show the same burden intensity (Steen-Olsen et al., 2014; Su et al., 2010). Tables with more sectors will lead to more accurate results, yet they require more data that are hard to gather in practice, particularly when combining national tables into multi-regional ones. This limitation also applies to the level of aggregation of countries, some of which are often merged into lumped regions, like the RoW region. In the case of the WIOD, the region labelled as RoW contains very different countries with very diverse economic structures and, therefore, pollution patterns (e.g. Switzerland vs Syria). This RoW region represents $35 \%$ of the global population and $14 \%$ of the total GDP. Despite these limitations, the WIOD database has been used intensively in the literature, and its level of spatial aggregation is widely accepted in the scientific community (Arto et al., 2014; Cansino et al., 2016; Feng et al., 2015; Kaltenegger et al., 2017; Löschel et al., 2015, 2013; Mundaca et al., 2015; Timmer et al., 2015; Wu et al., 2017; Xu and Dietzenbacher, 2014; Zhang et al., 2015).

- Multi-regional input-output tables are constructed from national accounts (in the form of supplyand-use tables (SUTs)) as well as from statistical data on international trade. As already mentioned, gathering the necessary regional economic and environmental information and processing the corresponding data is highly time consuming. Because of this, up-to-date tables are very seldom available. Our analysis covers the period from 1995 to 2009, yet the trends observed and the general conclusions drawn might not change significantly for longer periods as the annual rates of change in Gini values are low and tend to vary little over time.

- The estimates of the inequality levels we provide in our work are conservative for two main reasons. First, we quantify what is known as type two inequality, where all individuals within a country are assumed to be responsible for the same level of burden (or GDP). As discussed elsewhere for the economic Gini (Milanovic, 2013), type two inequality has been decreasing for decades, whereas "true" inequality (type three) has remained almost constant. This could very likely happen in the case of environmental inequality. Moving to the "true" global inequality, where each single individual enters in the calculations with its own actual burden, would require gathering individual-based data for many regions and burdens, which would be a very difficult if not impossible task. Furthermore, additional assumptions regarding the consumption patterns of the population would be required, thereby introducing higher levels of uncertainty in the calculations. The second reason for our results to be conservative is that we assume that there is full equality in the distribution of burdens among the citizens of the RoW region. As mentioned earlier, the RoW region aggregates countries with different pollution patterns and per-capita wealth. Bearing both issues in mind, we conclude that our Gini estimates represent a lower bound on the "true" Gini that would be obtained by using more detailed data in the calculations. Hence, environmental inequality levels might well be above our estimates, reinforcing our message on the need to tackle inequality with urgency.

- Our holistic approach aims to make progress towards a more sustainable future by integrating the vertical and horizontal dimensions of sustainability. We argue that this goal should be attained by defining quantitative environmental inequality targets together with thresholds on the total burdens generated. Unfortunately, environmental inequality is not explicitly considered in the $2030 \mathrm{UN}$ Agenda and, therefore, quantitative targets are currently missing in the Sustainability Development Goals (Cobham, 2013; Cobham et al., 2013; Engberg-Pedersen, 2013; Lang and Lingnau, 2015). Lacking official targets, we propose to define them using an inequality barometer that considers two criteria: (i) the role in satisfying human needs; and (ii) the current inequality level. This tool could be used as a starting point to trigger further discussions and articulate negotiations aimed at reaching a consensus on inequality targets. With regards to the global limits on burdens, it should be noted that they have only been estimated for a handful of burdens and are subject to significant uncertainties (Hoekstra and Wiedmann, 2014; Rockström et al., 2009b; Steffen et al., 2015). Further research and efforts are therefore needed to establish unambiguously the Earth's ecological limits for several burdens. This would ultimately ensure a safe operation leading to a more resilient planet.

- This work proposes a top-down systems approach to determine regional per-capita consumption quotas to demonstrate how optimisation models can be used to tackle inequalities and support decisions in policy-making. Our formulation could be further enhanced and refined by incorporating additional constraints to model regional vulnerabilities to local impacts, the detailed productive structure of regions, additional criteria relevant for stakeholders, and technology curves describing the evolution of technologies over time, among others.

- Note that in order to ensure that the Gini limit considered in our model is not exceeded in practice, it is necessary that the quotas defined for each country are satisfied as a strict equality. That is, if 
a country is allocated a quota but then ends up generating an amount of burden strictly below its quota, then the burden Gini will likely differ from the bound considered in the optimisation. In practice, due to their economic growth countries are expected to naturally increase their per-capita burdens until eventually reaching their quota. Hence, it is likely that quotas will be fully met. However, some countries might operate in a region strictly below their quota. This might imply that the country is satisfied with the Gini attained at that level of consumption, as otherwise it would keep on increasing the amount of burden generated. There is, therefore, no point in artificially forcing the countries to match their quota. Hence, our model provides the countries with enough flexibility to decide whether they wish to exhaust their quota or not, and in case they do so, it ensures that the maximum Gini is not surpassed.

- Note that to attain a truly sustainable development, all burdens should be considered simultaneously (Sustainable agriculture, 2018). Approaching targets for only a few burdens may lead to what is known as burden shifting, where the environmental impact may be displaced from one environmental problem to another and/or from some regions to others. For instance, replacing fossil fuels by biomass in the mix might reduce $\mathrm{CO}_{2}$ emissions, but at the expense of increasing water and land use impacts. Therefore, a potential refinement of the model should focus on establishing targets on multiple burdens simultaneously. This would require extra constraints to model the associated synergies and interactions, which would likely be affected by additional uncertainties. In addition, it is important to understand that the CB environmental burdens considered in this study are embodied in the products and services traded between regions, which makes it even more difficult to design concrete policies aiming at diminishing the risk of burden shifting. We, therefore, decided to leave these aspects of the problem open for further developments.

\section{References}

Addams, L., Boccaletti, G., Kerlin, M., Stuchtey, M., 2009. Charting our water future: economic frameworks to inform decision-making. McKinsey Company, New York.

Arto, I., Rueda-Cantuche, J.M., Peters, G.P., 2014. Comparing the GTAP-MRIO and WIOD databases for carbon footprint analysis. Econ. Syst. Res. 26, 327-353.

Biewen, M., 2012. Additive decompositions with interaction effects. IZA Discuss. Pap. No. 6730.

Biewen, M., 2014. A general decomposition formula with interaction effects. Appl. Econ. Lett. 21, 636642. https://doi.org/10.1080/13504851.2013.879280

Brooke, A., Kendrick, D., Meeraus, A., Raman, R., 1998. GAMS—A User'sManual. GAMS Development Corporation, Washington, DC.

Cansino, J.M., Román, R., Ordóñez, M., 2016. Main drivers of changes in CO2 emissions in the Spanish economy: A structural decomposition analysis. Energy Policy 89, 150-159.

Cobham, A., 2013. Palma vs. Gini: Measuring Post-2015 Inequality. Cent. Glob. Dev. Blog 4.

Cobham, A., Sumner, A., Cornia, A., Dercon, S., Engberg-pedersen, L., Evans, M., Lea, N., Lustig, N., Manning, R., Milanovic, B., 2013. Putting the Gini back in the bottle?'The Palma'as a policyrelevant measure of inequality.

Cortés-Borda, D., Guillén-Gosálbez, G., Jiménez, L., 2015. Assessment of nuclear energy embodied in international trade following a world multi-regional input-output approach. Energy 91, 91-101. https://doi.org/10.1016/j.energy.2015.07.117

Dalin, C., Wada, Y., Kastner, T., Puma, M.J., 2017. Groundwater depletion embedded in international food trade. Nature 543, 700.

Davis, S.J., Peters, G.P., Caldeira, K., 2011. The supply chain of CO2 emissions. Proc. Natl. Acad. Sci. U. S. A. 108, 18554-9. https://doi.org/10.1073/pnas.1107409108

Dietzenbacher, E., Los, B., Stehrer, R., Timmer, M., De Vries, G., 2013. The construction of world input-output tables in the WIOD project. Econ. Syst. Res. 25, 71-98.

Economic, U.N.D. of, 2001. Indicators of sustainable development: Guidelines and methodologies. United Nations Publications.

Engberg-Pedersen, L., 2013. Development goals post 2015: Reduce inequality. DIIS.

European Commission, 2017. CAP context indicators 2014-2020 Annexes.

Feng, K., Davis, S.J., Sun, L., Hubacek, K., 2015. Drivers of the US CO 2 emissions 1997-2013. Nat. Commun. 6, 7714.

Hoekstra, A.Y., Wiedmann, T.O., 2014. Humanity's unsustainable environmental footprint. Science 344, 1114-7. https://doi.org/10.1126/science.1248365

Kaltenegger, O., Löschel, A., Baikowski, M., Lingens, J., 2017. Energy costs in Germany and Europe: An assessment based on a (total real unit) energy cost accounting framework. Energy Policy $104,419-430$. 
Kwakkel, J.H., Timmermans, J.S., 2012. Blue limits of the Blue Planet: an exploratory analysis of safe operating spaces for human water use under deep uncertainty, in: CESUN 2012: 3rd International Engineering Systems Symposium, Delft University of Technology, The Netherlands, 18-20 June 2012.

Lang, V.F., Lingnau, H., 2015. Defining and Measuring Poverty and Inequality Post-2015. J. Int. Dev. 27, 399-414.

Leontief, W.W., 1936. Quantitative input and output relations in the economic systems of the United States. Rev. Econ. Stat. 105-125.

Löschel, A., Pothen, F., Schymura, M., 2015. Peeling the onion: Analyzing aggregate, national and sectoral energy intensity in the European Union. Energy Econ. 52, S63-S75.

Löschel, A., Rexhäuser, S., Schymura, M., 2013. Trade and the environment: An application of the WIOD database. Chinese J. Popul. Resour. Environ. 11, 51-61.

Ma, M., Cai, Wei, Cai, Weiguang, Dong, L., 2019. Whether carbon intensity in the commercial building sector decouples from economic development in the service industry? Empirical evidence from the top five urban agglomerations in China. J. Clean. Prod. 222, 193-205. https://doi.org/10.1016/j.jclepro.2019.01.314

Milanovic, B., 2013. Global income inequality in numbers: In history and now. Glob. policy 4, 198-208.

Miller, R.E., Blair, P.D., 2009. Input-Output Analysis: foundations and extensions. Cambridge Univ. Press 1-784. https://doi.org/10.1017/CBO9781107415324.004

Mundaca, L., Román, R., Cansino, J.M., 2015. Towards a Green Energy Economy? A macroeconomic-climate evaluation of Sweden's CO2 emissions. Appl. Energy 148, 196-209.

Pascual-González, J., Guillén-Gosálbez, G., Mateo-Sanz, J.M., Jiménez-Esteller, L., 2015. Statistical analysis of global environmental impact patterns using a world multi-regional input-output database. J. Clean. Prod. 90, 360-369. https://doi.org/10.1016/j.jclepro.2014.11.065

Peters, G.P., 2008. From production-based to consumption-based national emission inventories. Ecol. Econ. 65, 13-23. https://doi.org/10.1016/j.ecolecon.2007.10.014

Peters, G.P., Minx, J.C., Weber, C.L., Edenhofer, O., 2011. Growth in emission transfers via international trade from 1990 to 2008. Proc. Natl. Acad. Sci. U. S. A. 108, 8903-8. https://doi.org/10.1073/pnas.1006388108

Rockström, J., Steffen, W., Noone, K., Persson, Å., Chapin, F.S., Lambin, E., Lenton, T.M., Scheffer, M., Folke, C., Schellnhuber, H.J., Nykvist, B., de Wit, C.A., Hughes, T., van der Leeuw, S., Rodhe, H., Sörlin, S., Snyder, P.K., Costanza, R., Svedin, U., Falkenmark, M., Karlberg, L., Corell, R.W., Fabry, V.J., Hansen, J., Walker, B., Liverman, D., Richardson, K., Crutzen, P., Foley, J., 2009a. Planetary boundaries: Exploring the safe operating space for humanity. Ecol. Soc. 14.

Rockström, J., Steffen, W., Noone, K., Persson, A., Chapin, F.S., Lambin, E.F., Lenton, T.M., Scheffer, M., Folke, C., Schellnhuber, H.J., Nykvist, B., de Wit, C.A., Hughes, T., van der Leeuw, S., Rodhe, H., Sörlin, S., Snyder, P.K., Costanza, R., Svedin, U., Falkenmark, M., Karlberg, L., Corell, R.W., Fabry, V.J., Hansen, J., Walker, B., Liverman, D., Richardson, K., Crutzen, P., Foley, J.A., 2009b. A safe operating space for humanity. Nature 461, 472-5. https://doi.org/10.1038/461472a

Steen-Olsen, K., Owen, A., Hertwich, E.G., Lenzen, M., 2014. Effects of sector aggregation on CO2 multipliers in multiregional input-output analyses. Econ. Syst. Res. 26, 284-302.

Steffen, W., Richardson, K., Rockstrom, J., Cornell, S.E., Fetzer, I., Bennett, E.M., Biggs, R., Carpenter, S.R., de Vries, W., de Wit, C.A., Folke, C., Gerten, D., Heinke, J., Mace, G.M., Persson, L.M., Ramanathan, V., Reyers, B., Sorlin, S., 2015. Planetary boundaries: Guiding human development on a changing planet. Science (80-. ). 347. https://doi.org/10.1126/science.1259855

Steinberger, J.K., Timmons Roberts, J., Peters, G.P., Baiocchi, G., 2012. Pathways of human development and carbon emissions embodied in trade. Nat. Clim. Chang. 2, 81-85. https://doi.org/10.1038/nclimate1371

Su, B., Huang, H.C., Ang, B.W., Zhou, P., 2010. Input-output analysis of CO2 emissions embodied in trade: The effects of sector aggregation. Energy Econ. 32, 166-175. https://doi.org/10.1016/j.eneco.2009.07.010

Sun, J., 1998. Changes in energy consumption and energy intensity: a complete decomposition model. Energy Econ. 20, 85-100.

Sustainable agriculture, 2018. . Nat. Sustain. 1, 531. https://doi.org/10.1038/s41893-018-0163-4

Timmer, M., Erumban, A.A., Gouma, R., Los, B., Temurshoev, U., de Vries, G.J., Arto, I., Genty, V.A.A., Neuwahl, F., Francois, J., 2012. The world input-output database (WIOD): contents, sources and methods. Institue for International and Development Economics.

Timmer, M.P., Dietzenbacher, E., Los, B., Stehrer, R., de Vries, G.J., 2015. An Illustrated User Guide 
to the World Input-Output Database: The Case of Global Automotive Production. Rev. Int. Econ. 23, 575-605. https://doi.org/10.1111/roie.12178

United Nations, 2017. United Nations Department of Economic and Social Affairs/Population Division (2017): World Population Prospects: The 2017 Revision.

Wiedenhofer, D., Guan, D., Liu, Z., Meng, J., Zhang, N., Wei, Y.-M., 2017. Unequal household carbon footprints in China. Nat. Clim. Chang. 7, 75.

Wiedmann, T., 2009a. A review of recent multi-region input-output models used for consumptionbased emission and resource accounting. Ecol. Econ. 69, 211-222. https://doi.org/10.1016/j.ecolecon.2009.08.026

Wiedmann, T., 2009b. A review of recent multi-region input-output models used for consumptionbased emission and resource accounting. Ecol. Econ. 69, 211-222. https://doi.org/10.1016/j.ecolecon.2009.08.026

Wiedmann, T., Wilting, H.C., Lenzen, M., Lutter, S., Palm, V., 2011. Quo Vadis MRIO? Methodological, data and institutional requirements for multi-region input-output analysis. Ecol. Econ. 70, 1937-1945. https://doi.org/10.1016/j.ecolecon.2011.06.014

The World Band, n.d. World Development Indicators - DataBank [WWW Document]. http://databank.worldbank.org/data/reports.aspx?source=world-development-indicators (accessed 7.6.17).

Wu, R., Geng, Y., Liu, W., 2017. Trends of natural resource footprints in the BRIC (Brazil, Russia, India and China) countries. J. Clean. Prod. 142, 775-782.

$\mathrm{Xu}, \mathrm{Y}$., Dietzenbacher, E., 2014. A structural decomposition analysis of the emissions embodied in trade. Ecol. Econ. 101, 10-20. https://doi.org/10.1016/j.ecolecon.2014.02.015

Zhang, W., Peng, S., Sun, C., 2015. CO2 emissions in the global supply chains of services: An analysis based on a multi-regional input-output model. Energy Policy 86, 93-103. 